\title{
Complementarity between herbaceous and woody plants in providing resources for bees in a semi-arid tropical climate: insights for conservation
}

Fermín J. Chamorro ( $\square$ ferminchamorro@gmail.com )

Universidade Federal do Ceará https://orcid.org/0000-0002-2481-5656

Christiana M.A. Faria

Universidade Federal do Ceara

Breno M. Freitas

Universidade Federal do Ceara

Francisca S. Araújo

Universidade Federal do Ceara

\section{Research Article}

Keywords: Caatinga, floral resources, growth forms, life forms, phenology

Posted Date: May 4th, 2021

DOl: https://doi.org/10.21203/rs.3.rs-230866/v1

License: (c) (i) This work is licensed under a Creative Commons Attribution 4.0 International License.

Read Full License 
1 Complementarity between herbaceous and woody plants in providing resources for bees

2 in a semi-arid tropical climate: insights for conservation

3

4 Fermín J. Chamorro ${ }^{1,}$, Christiana M. A. Faria ${ }^{1}$, Breno M. Freitas ${ }^{1,2}$, Francisca S. Araújo ${ }^{1}$

5

61 Programa de Pós-graduação em Ecologia e Recursos Naturais, Departamento de Biologia,

7 Campus do Pici, Universidade Federal do Ceará, Fortaleza - CE, CEP 60440-900, Brazil.

82 Setor de Abelhas, Departamento de Zootecnia, Campus do Pici, Universidade Federal do

9 Ceará, Fortaleza - CE, CEP 60356-000, Brazil.

10

* Corresponding author: ferminchamorro@gmail.com

FJC ORCID: 0000-0002-2481-5656

CMAF ORCID 0000-0001-9657-4655

BMF ORCID 0000-0002-9932-2207

FSA ORCID: 0000-0003-4661-6137

Few phenology studies look at all species with different life and growth forms. We

demonstrate why this approach is a more effective way to evaluate resources for bees and inform conservation actions.

Authors' contributions: FJC and FSA conceived and designed the study. FJC performed fieldwork and conducted data analyses. FJC wrote the manuscript with help of CMAF and inputs from BMF and FSA. All authors revised the manuscript. 


\section{Abstract}

The distribution of floral resources in time and space varies according to vegetation strata and to the influence of precipitation and photoperiod on flowering patterns. There are scarce studies jointly investigating the spatio-temporal distribution of plant resources for bees and at the community level, which are critical for planning strategies for their conservation. Here we investigated how herbaceous and woody strata integrate to provide resources (e.g. nectar, pollen, oil) for bees inhabiting fragments of Caatinga dryforest in the northeastern Brazil. We assessed herbaceous and woody strata species composition, abundance and their floral phenodynamics for 18 months in three 0.5 -ha plots. We registered bee's plant visits and collected data on abiotic factors to examine how they correlate to flowering patterns. Bees visited approximately $80 \%$ of the plant community, composed by a variety of growth (e.g. trees, shrubs, lianas) and life (e.g. phanerophytes, chamaephytes, hemicryptophytes, and therophytes) forms. Water availability was the main variable correlated to arboreal and herbaceous flowering, but photoperiod also played a role in annual and interannual flowering patterns. Both woody (52\%) and herbaceous components (48\%) similarly contributed to nectar and pollen supplies, while trees were also a source of resin. Herbaceous life forms flowered sequentially during the rainy season, keeping continuous supply until the beginning of the dry season. While growth forms in the woody stratum provided resources relatively constantly throughout the year. The phenological complementarity between different life and growth forms should be considered in bee conservation strategies, aiming to optimize resource availability throughout the year.

Keywords: Caatinga, floral resources, growth forms, life forms, phenology. 


\section{Introduction}

Bees have an estimated diversity of 20,000 species and are one of the main biotic pollination agents on a global scale. Their importance as pollinators is linked to their strong dependence on floral resources, mainly pollen and nectar (Michener 2007). Bee pollination service benefits approximately $75 \%$ of flowering plants and $80 \%$ of crops (Klein et al. 2007; Ollerton et al. 2011). Despite their ecological and economic importance, bees have been severely threatened by human activities, i.e., land-use change, agricultural intensification, and use of pesticides. These activities mainly cause the loss of floral resources leading to the decline of bee populations (Potts et al. 2010; Goulson et al. 2015). Furthermore, changes associated with the Anthropocene climate crises (i.e., temperature rises and increases in the frequency of extreme events, such as droughts; IPCC 2014), are likely to decrease the quality and quantity of floral supplies or promote their total loss, posing an even more significant threat to bee populations (Wagner 2020). Therefore, the safeguarding of floral resources is crucial for bees' survival, and their continuum availability throughout seasons is one of the main factors regulating bee populations and diversity (Roulston and Goodell 2011).

How floral resources influence bee populations depends on plant diversity and stratification, and flowering phenodynamics (i.e., flowering duration, total floral abundance, species richness, turnover, scarcity, and resource pulses; Ogilvie and Forrest 2017). Plant diversity and vertical stratification offers a range of resources available at different heights within the plant community. Resources may then be collected, simultaneously or complementarily, at different times of the day or seasonal periods, by a variety of pollinator groups, contributing to the coexistence of species (Aguiar et al. 2013; Venjakob et al. 2016). In turn, climatic factors, such as, rainfall, temperature, and photoperiod, control triggering and duration of 
flowering phenodynamics (Forrest and Miller-Rushing 2010), also imposing restrictions on bee foraging (Ogilvie et al. 2017; Lawson and Rands 2019).

The importance of plant communities for bees goes beyond floral resources such as pollen, and nectar. It also includes the supply of nesting resources (i.e. extrafloral resin) and other floral and extra floral resources. For example, bees of the Centridini and Tapinotaspidini tribes collect oils produced in floral glands (elaiophores) to feed their offspring, in replacement to nectar (Michener 2007). Different bee groups use extrafloral resins in nest construction as a protective barrier against microorganisms. These resins tend to be continuously available throughout the year in the plant community (Roubik 1989). Thus, understanding the availability of nesting resources, floral and non-floral food resources is necessary to maintain healthy bee populations (food supply and protective substances) and their species diversity (Requier and Leonhard 2020).

Considering the role of plant diversity in resource supply and the influence of annual climate variation on flowering patterns and, consequently, on the availability of floral resources, studies on floral phenodynamics provide key knowledge for bee conservation, particularly in the face of anthropogenic changes (Morellato et al. 2016). However, such studies should consider an analysis of plant community and its floral phenodynamics that includes life and growth forms (see Monasterio and Sarmiento 1976, Cortés-Flores et al. 2017, Nagahama and Yahara 2019). Life form synthesizes the morphological characteristics linked to the way plants obtain resources to survive in the unfavorable season (Raunkiaer 1934) and growth form describes the community structure (Whittaker 1975). Therefore, the inclusion of those plant attributes to describe phenological patterns allows a better understanding of the influence of abiotic factors on flowering patterns and consequently the distribution of 
resources available to pollinators within the community. Also, it is important to considerer all species and their respective relative abundances in the community to fully understand the availability of the floral resources. Such community-level analysis enables to quantify how much each plant species contributes resources locally and spatially, thus benefiting bee's populations.

Phenological studies taking a community approach, as described above, and with a perspective of resource availability particularly for pollinators have not been fully explored in the literature (see Pereira et al. 1989, Rodarte et al. 2008, Quirino and Machado 2014, Aleixo et al. 2014). This information is necessary not only to infer about possible responses of bee populations to ever-changing environments but also to create and implement strategies for the sustainable use of vegetation that ensure the conservation of bee communities and, consequently, the maintenance of pollination as an ecosystem service (IPBES 2016). Most conservation actions implemented so far world widely have been focused on one vegetation component, herbaceous or woody, without considering the phenological complementarity between these components in providing resources for bees (see Garrat et al. 2017, Donkerseley 2019, Timberlake et al. 2019, Requier and Leonhard 2020). Phenological complementarity is fundamental in bee conservation strategies, in particular, to reduce the effects of the temporal deficit of floral resources (Timberlake et al. 2019).

In the northeast Brazilian semi-arid region, floral and non-floral resources have been mainly diminished by deforestation, and they are likely to become more reduced by the Anthropocene climate crisis in the coming decades (Silva et al. 2019). The predicted temperature rises and increase in the frequency of drought events will probably lead to an impoverishment of the local vegetation, an increase of land vulnerability and a growth of 
desertification areas (Marengo and Bernasconi 2015). As a consequence, less structurally complex and diverse environments are expected, and there will be a reduction in the number of plant species with different growth habits and specialized pollination systems, directly affecting resource supplies for bees (Silva et al. 2019)

Given the knowledge gap on resources availability for bees from the whole plant community and the vulnerability of Brazilian semi-arid vegetation to land use and climate crisis, we analyzed the availability of floral and non-floral supplies for bees at the community level in three fragments of Caatinga, northeast Brazil. The Caatinga is a seasonally dry forest located in the Brazilian semi-arid region, classified as Tropical Savanna sensu Gardner et al. (2020). It is a good study model because it harbors different vegetation growth (trees, shrub, herbs, and lianas) and life (phanerophytes, chamaephytes, hemicryptophytes, cryptophytes, and therophytes) forms (Costa et al. 2007, Quirino and Machado 2014). Also, because insect pollination occurs for $70 \%$ of Caatinga plant species, being bees the main pollinator group (Machado and Lopes 2004). Finally, Caatinga climate has high temperatures and frequent drought periods, which replicates the predictions of climate change, offering an opportunity to discuss potential effects of the anthropogenic climate crisis on the supply of resources for bees.

The main questions addressed in the present study were: i) what are the proportions of the plant community and the different vegetation components (herbaceous and woody strata) that provide resources to bees, and what types of resources? ii) how are the annual flowering dynamics in the woody and herbaceous components considering the different life and growth forms, and how does this reflect in the availability of floral resources for bees? iii) how does 
the resource availability in each stratum respond to the intra-annual variation in water availability (rainfall and soil moisture)?

\section{Material and methods}

\section{Study area}

The study area is located in the northeastern Brazil semi-arid region (Fig. S1A), known as the Caatinga Domain (Andrade-Lima 1981) or the Drought Polygon (Polígono das secas). The Caatinga Domain has approximately $1,128,697 \mathrm{~km}^{2}$ (Brasil MI 2018). Its altitudes vary between 20 and $500 \mathrm{~m}$ a.s.l. (Moro et al. 2016). The total average annual rainfall ranges from 400 to $800 \mathrm{~mm}$ (Souza et al. 1992), which is usually concentrated in 3-5 months. The annual pattern is erratic with drought years occurring every 3-4 decades and lasting 3-5 years (Sampaio 1995). According to the Köppen system, the semi-arid climate (BSh) predominates in the Caatinga, with summer and autumn rains and dry winter (Alvares et al. 2014). The climate zone corresponding to that classification in the Gardner et al. (2020) system is Tropical Savanna.

The present study was carried out at the Vale do Curu Experimental Farm of the Federal University of Ceará, located in the municipality of Pentecoste, state of Ceará (Latitude: $3^{\circ} 48^{\prime}$ South, Longitude: $39^{\circ} 20^{\prime}$ West and 80 m a.s.1.) (Fig. S1B). The farm occupies 823 ha, including irrigated crop zones and native vegetation fragments at different stages of secondary regeneration (15-50 years). Based on data from the meteorological station located in the farm (Fig. S1B), the rainfall is concentrated in the first half of the year, usually between January and May, and presents a historical annual average of 759 mm (1970-2019) (Fig. S2A). During 
the rest of the year, there is water deficiency in the area that can last from 7 to 11 months. The temperature is high, with an annual average of $28.3{ }^{\circ} \mathrm{C}$ (Fig. S2A), which results in high potential evapotranspiration (on average, 1,500 $\mathrm{mm}$ per year).

The Caatinga vegetation shows a woody stratum mostly composed of deciduous tree species, many of them bearing thorns. The treetops do not form a real canopy, whose average opening is $18 \%$ in the rainy season and $89 \%$ in the dry season when the trees lose almost all their leaves (Fig. S3). This canopy opening facilitates the growth of an herbaceous layer composed mainly of annual plants (therophytes), whose richness can be two to three times higher than that of the woody component (see Costa et al. 2007). Succulent plants, especially Cactaceae, are common in both herbaceous and woody strata. As the study area is located near the Curu River, it also has floristic elements of riparian vegetation (see Moro et al. 2015).

\section{Data collection}

We selected three Caatinga fragments with more than 30 years of natural secondary regeneration and installed a 0.5 ha plot $(50 \times 100 \mathrm{~m})$ in each, considering $2-\mathrm{km}$ equidistance between them (Fig. S1B). This distance between plots was required to ensure independence when sampling bee data, as 1-2 km radius is the foraging area for most bee species (Greenleaf et al. 2007). We collected data on floral phenodynamics for 18 months (August 2017February 2019) in these three established plots.

We divided the three plots into $5010 \times 10 \mathrm{~m}$ subplots to identify the floristic composition and the abundance of each species per plot, analyze the floral phenodynamics, and determine floral resources availability for bees. We monthly assessed flowering activity of both woody 
and herbaceous components in each 50 subplots. To record woody flowering activity, we marked all woody individuals, which presented stem perimeter equal to or greater than $9 \mathrm{~cm}$ at the ground level, using metal tags and monthly assessed their flowering phenological state. This was done for all individuals of each species. We assessed flowering intensity of each woody plant (e.g. trees, shrubs and lianas) observed with flowers, using the semi-quantitative method of Fournier (1974). This method visually estimates the percentage of branches covered with flowers, classifying it in one of the five cover classes ( 0 to 4 range): $0=$ absence of phenophase, $1=1-25 \%, 2=26-50 \%, 3=51-75 \%$, and $4=76-100 \%$.

We assessed flowering in herbaceous strata with the semi-quantitative method of Daubenmire (1959), which also uses cover classes to estimate the population abundance of each species. Each month, we estimated the floral cover of herbaceous plants in 25 of the $5010 x 10 \mathrm{~m}$ subplots of each fragment (Fig.S1C). The selection of the 25 subplots for sampling the herbaceous component was random, using the Excel random function. To facilitate visual assessment of the cover, we used four $50 \times 50 \mathrm{~cm}$ PVC square within each of the 25 subplots, totaling $10050 \times 50 \mathrm{~cm}$ squares in each fragment (Fig. S1C). In each 50x50 cm square, we estimated the percentage of herbaceous cover and, based on this percentage, the percentage of individuals bearing flowers for each species. We used six classes to estimate floral cover per species: $1=$ up to $5 \%, 2=6-25 \%, 3=26-50 \%, 4=51-75 \%, 5=76-95 \%, 6=96-100 \%$.

Specialists identified plant taxonomic using exsiccates from samples of branches in the reproductive state (flower buds, flowers, or fruits), which were compared to specimens in the EAC Herbarium (Prisco Bezerra) of the Federal University of Ceará. The names of families, genera, and species were confirmed on the Flora do Brasil 2020 website 
(http://floradobrasil.jbrj.gov.br). We collected three specimens and deposited them at the EAC Herbarium for each species recorded with flowers in the plots.

Monthly, for one hour during two consecutive days in each plot (between 8:00 and 10:00), we observed the behavior of bees in flowers to determine whether a plant species was used as a supply source. Based on these observations, we determined whether bees collected nectar, pollen, oils, or resins from flowers. We also recorded whether bees collected resins or nectar from other parts of plants, such as the stem or extrafloral nectaries. Thus, we registered, for each plant species the provision of one or more of the following resources: nectar, pollen, oil, extrafloral nectar, floral resin, and extrafloral resin. When it was not possible to visualize a certain bee performing any type of foraging activity in a specific plant, we used information for that plant species available in the literature.

We also classified each plant species according to its growth and life forms and analyzed their phenodynamics. The classification by growth forms followed Whittaker (1975): trees, shrubs, lianas (woody vines), herbs, vines (herbaceous), and epiphytes. The classification of species into life forms followed Raunkiaer (1934), based on the level of protection of the buds and the reduction in the aerial part during the less favorable (dry) season: therophytes, cryptophytes, hemicryptophytes, chamaephytes, and phanerophytes. Lianas and arborescent cacti were considered phanerophytes, and, for the classification of vines, we followed the level of reduction of the aerial part during the dry season (see Raunkiaer 1934).

We collected data on rainfall ( $\mathrm{mm} / \mathrm{month})$, photoperiod (h/day), and water availability in the soil (\% soil moisture/month) to examine the correlation between abiotic factors and floral phenodynamics. This data allows us to discuss potential impacts of foreseen climate warming 
and drying on floral phenodymamics and bees' resource supply. Rainfall data were obtained from the meteorological station installed on the farm (Fig. 1A, Fig. S1B). The rainfall distribution pattern from September 2017 to February 2019 followed the historical record for the past 50 years (Fig. 1A, Fig. S2A). Although the annual rainfall for 2018 and 2019 felled above the historical average, until 2017 the area faced a long drought period that lasted almost six years (below the historical average) (Fig. S2B). The photoperiod data were obtained from the Brazilian Interactive Yearbook of the National Observatory (http://staff.on.br/jlkm/ephemeris/index.php). The maximum photoperiod was $12.20 \mathrm{~h} /$ day in December, and the minimum, $11.54 \mathrm{~h} /$ day in June (Fig. 1B).

We estimated the percentage of soil moisture based on the difference between the wet and dry weight (gravimetric method) of ten samples per plot per month. We selected ten of the 50 subplots to collect soil samples, spatially distributed to cover the plot area of 50x100 m (Fig. S1D). For this purpose, we divided the plot into three sections (30x50m, 40x50m, 30x50m), selecting three subplots in the first section, four in the second, and three in the third (Fig. S1D). Monthly, we selected different subplots per section and within each subplot we collected approximately $80 \mathrm{~g}$ of soil at $15-20 \mathrm{~cm}$ depth. In total 540 soil samples were collected and weighed on an analytical balance to three decimal places. We placed the samples in an oven at $100{ }^{\circ} \mathrm{C}$ for 72 hours to dry and then weighed them again. The water availability in the soil peaked in March 2018, with a delay of one month in relation to the beginning of rainy season, but as rainfalls increased, the response occurred in the same month (Fig. 1C-D).

\section{Data analysis}


We calculated the proportion of plant species visited by bees based on the total plant species bearing flowers recorded in each plot. To characterize this proportion, we calculated the proportion of species by stratum (woody, herbaceous), growth forms, life forms, and resource type. The characterization considered the total number of species visited by bees and the resource used (nectar and pollen). We used species activity and flowering intensity as metrics to describe the phenodynamics of floral resources. The species activity represents the proportion of the woody or herbaceous community in bloom per month in relation to the total of species visited by bees in the plot. Flowering intensity is a measure of floral abundance based on estimated floral cover data for both woody and herbaceous species. We calculated these metrics separately for each plot and by growth and life forms, considering the total of species visited by bees and the type of floral resource used (nectar and pollen).

To calculate the flowering intensity per month of the woody stratum, we divided the sum of all intensity values of the Fournier scale obtained for all individuals of each species by the maximum possible sum attributed to the woody component in each plot (i.e., the total number of individuals in the plot multiplied by four, the highest cover category on the Fournier scale). The flowering intensity of the herbaceous component represents the floral cover estimated monthly using the method of Daubenmire (1959). To estimate the floral cover of herbaceous plants, we calculated, monthly, the frequency per cover class (number of squares with the presence of flowering herbaceous plants per cover class: 1, 2, 3, 4, 5, and 6). Next, we multiplied this frequency by the class midpoint $(1=2.5,2=15,3=37.5,4=62.5,5=85$, and $6=97.5$ ) and added together all products of these multiplications to calculate an absolute floral cover value. To express this value in relative terms (\%), we divided the absolute cover value by the total number of squares sampled (100 each month). 
We built phenograms showing species activity and flowering intensity for both woody and herbaceous components to graphically characterize flowering dynamics and, consequently, the availability of floral resources for bees throughout the sampling period. For better visualization of temporal variations in species activity and flowering intensity, the phenograms were constructed based on kernel-smoothed estimates (bandwidth $=3$ ), using the ksmooth function of the stats package (R Core Team 2019).

We performed pairwise cross-correlations between rainfall, photoperiod, and soil moisture (abiotic factors) and community phenodynamics variables (species activity and flowering intensity), classified in life and growth forms, to understand the relationship influence of these abiotic factors (potentially explanatory variables) on flowering phenodynamics (target variables) and its implications on the availability of floral resources for bees. Crosscorrelation compares two temporal data series considering temporal lags in that relationship (Legendre and Legendre 2012). Thus, it is possible to identify whether changes in phenological events occur after changes in abiotic factors, lag time (lag), and the correlation between these changes (correlation coefficient). Before estimating cross-correlations, we removed any trend in the data because it needs to be stationary, that is, that the mean, variance, and other statistical properties of the distribution are constant throughout the series (Legendre and Legendre 2012).

We then built correlograms (cross-correlation graphs) to visualize pairwise cross-correlations. In the graph, the negative lag indicates that the phenological event occurred after the change in the abiotic factor, and the positive lag indicates that the phenological event preceded the abiotic factor. The cross-correlation coefficient at zero lag has the same value as Pearson's linear correlation coefficient, showing that the series occur simultaneously, with no lag 
between the data. Therefore, it indicates a response in the same month of the change in the abiotic factor. We used the $c c f$ function (stats package) to calculate correlations and built correlograms and, the detrend function (pracma package, Borchers 2019) to remove the trend in the data. All functions were performed on the R platform (R Core Team 2019).

\section{Results}

\section{Floristic composition and diversity of floral resources}

In total, we analyzed the floral phenodynamics of 4402 individual woody plants, belonging to 38 morphospecies, 34 genera, and 18 families, recorded in the three 0.5 ha sampling plots. The families with the largest number of species were Fabaceae (10 spp.), Euphorbiaceae (6 spp.), and Bignoniaceae ( 3 spp.). The number of individuals and species by plot were: plot 1 (1634 ind, 31 spp.), plot 2 (1180 ind, 25 spp.), and plot 3 (1588 ind, 25 spp.). The woody species with the highest relative density per plot were Sebastiania macrocarpa (18\%), Croton blanchetianus (17\%), Combretum leprosum (10\%), Cenostigma bracteosum (9\%), Mimosa caesalpiniifolia (6\%), Cordia oncocalyx (5\%), Piptadenia stipulacea (4\%), Amburana cearensis (4\%), Bauhinia cheilantha (4\%), and Fridericia sp (Table S1).

\section{For the herbaceous component, we recorded 44 morphospecies, grouped into 32 genera and} 16 families in the three 0.5 ha sampling plots. The most speciose families were Asteraceae ( 8 spp.), Fabaceae (5 spp.), Acanthaceae, Commelinaceae, and Convolvulaceae (4 spp. each). The morphospecies with the highest cover percentage were Ruellia paniculata (15\%), Commelina erecta (7\%), Dicliptera mucronifolia (6\%), Justicia aff. thunbergioides (5\%), 
Ipomoea sp.3 (4\%), Desmodium sp. (3\%), Alternanthera brasiliana (3\%), Spermacoce sp. 2 (3\%), Oxalis divaricata (3\%), and Mesosphaerum suaveolens (2\%) (Table S1).

The total flora analyzed in the three plots included 82 species ( 44 herbaceous and 38 woody). Of these, 69 were visited by bees: $40(90 \%)$ herbaceous morphospecies and $29(76 \%)$ woody species, representing $84 \%$ of the total species found in the community. However, in the individual analysis by plot, the woody and herbaceous strata showed similar relative importance in the proportion of species/morphospecies visited by bees (Fig. 2, Fig. S4). Although we recorded bees visiting all types of growth forms (trees, shrubs, lianas, herbs, and vines), they mostly visited trees (38\%) and herbs (41\%) (Fig. 2, Fig. S4). The classification by life forms showed that bees visited phanerophytes, chamaephytes, hemicryptophytes, and therophytes, but phanerophytes (52\%) and therophytes (26\%) were the two life forms with the highest percentage of species visited (Fig.2, Fig. S4). Regarding the type of floral resource, $50 \%$ of plant species were visited for both nectar and pollen (classified as nectarpolliniferous), while $42 \%$, were visited for exclusively one of the two (25\% nectar, $17 \%$ pollen, Fig.S4). The remaining $8 \%$ corresponded to a single species visited for oil (Angelonia sp., Portulacaceae) and four other species visited for resins only (S. macrocarpa) or for resins, nectar, and/or pollen together (C. bracteosum, C. blanchetianus, Myracrodruon urundeuva) (Fig. S4, Table S1).

Nectar and pollen availability were analyzed separately per growth and life forms by stratum. We found similar proportions of species in the two strata (51\% woody and $49 \%$ herbaceous) providing pollen and a relatively higher proportion of woody species providing nectar (59\% woody and $41 \%$ herbaceous) for bees (Fig. 2). This difference reflects a great proportion of tree and liana species providing nectar in the woody stratum. We recorded bees visiting lianas 
only for nectar (Fig. 2). Among herbaceous plants, the proportion of chamaephytes and therophytes species providing nectar was similar $(\sim 20 \%)$, but the proportion of therophytes providing pollen was higher (29\%) than chamaephytes (12\%). Hemicryptophytes only provided pollen (Fig. 2). Only the woody component (trees) provided resins, and a therophyte species provided oils (Table S1).

\section{Phenodynamics of floral resources}

In general, considering the three plots (landscape level), we recorded a continuous availability of floral resources in 17 out of the 18 months studied. However, species activity and flowering intensity peaks occurred mainly in the transition period (May-July) from the rainy to the dry season in 2018 (Fig. 3, Fig. 4). The woody stratum showed activity in 15 out of the 18 months and the herbaceous stratum in 10 out of the 18 months analyzed. Simultaneous activity of both two strata occurred in periods of four to six months, which defined the peak of floral resources (Fig. 3, Fig. 4). The period of the highest resource availability (more species active and more intense flowering) was shorter for nectar (April to August 2018, Fig. 3, Fig.

4) than the period of pollen availability, which lasted from January to August 2018 (Fig. 3, Fig. 4). Oil was available only in June 2018, with a cover percentage below $1 \%$ of the plot (Table S1).

Out of the 29 phanerophyte species visited by bees, only 16 showed flowering activity during the study. However, the activity was well distributed among months (one or two different species bloomed each month per plot) (Fig. 3). Regarding flowering intensity of the woody component, we recorded two peaks, the first in February 2018, at the beginning of the rainy season, exclusively by the flowering of $C$. blanchetianus trees, and the second, between May 
and August 2018, at the end of the rainy season and the beginning of the dry season, mainly by the flowering of the A. cearensis trees (Fig. 3). Trees were the main resource supply in the rainy season and in the beginning of the dry season, when we recorded higher species flowering activity (Fig. 4). While shrubs and lianas stood out during the last months of the dry season (October-December) and in the transition between the dry and rainy seasons (December-January) (Fig.4). Together, these different growth forms kept flowering supply for bees during all seasons

Herbaceous species flowering activity concentrated in the rainy season (February-May 2018) and in the beginning of the dry season (June-September 2018), with species activity and flowering intensity peaks in May, with up to 15 species flowering simultaneously per plot (55\% of species) (Fig. 3, Fig. 4). The analysis by life forms revealed that the first species bearing flowers were hemicryptophytes (maximum activity in February), followed by terophytes (maximum activity in May), and chamaephytes (maximum activity in July), whose flowering extended until September, with $R$. paniculata being the only chamaephyte species active in that month (Fig. 3, Table S1).

\section{Correlation of flowering phenodynamics with abiotic factors}

Life and growth forms cross-correlation analysis allowed us to verify the relationship of between abiotic factors and flowering phenodynamics of the herbaceous and woody strata (Fig. 5). We found significant positive correlations in the woody strata between tree's phenodynamics (species activity and flowering intensity) and rainfall and water availability in the soil, with a three to four months lag. The correlation between tree's phenodynamics and photoperiod was significantly negative and showed no time lag, indicating a prompt response 
to the decrease in the number of light hours per day. Shrub's activity pattern was the opposite

424 of trees, showing a significant positive correlation with increased photoperiod and negative

425

426

427 correlations with decreased rainfall and water availability in the soil. Correlations were positives but not significant for shrub's flowering intensity. Lianas' phenodynamics was positively correlated with rainfall and soil moisture, but started a month in advance (positive lag), indicating a rapid response to the first rains, i.e., those that started before the peak of water availability (maximum rainfall and soil moisture) of the rainy season (Fig. 5). Their correlation with photoperiod was positive but not significant.

In general, herbaceous flowering phenodynamics showed a significant positive correlation with rainfall and soil moisture and a negative correlation with photoperiod, showing a direct response to both the increase of water availability and the decrease in the number of light hours per day (Fig. 5). However, the time lag or advance in relation to abiotic factors differed among life forms. Chamaephytes showed a time lag (three months) in relation to the peak of water availability but not in relation to the decrease in photoperiod (Fig. 5).

Hemicryptophytes did not show a time lag in relation to the peak of water availability but showed a time advance (three months) in relation to the minimum photoperiod (Fig. 5). Finally, therophytes showed an intermediate pattern between cryptophytes and hemicryptophytes, with two months lag in relation to the peak of water availability and one month in advance before the minimum photoperiod (Fig. 5).

\section{Discussion}

Our results showed that approximately $80 \%$ of species from both herbaceous and woody strata constitute an important source of floral and non-floral resources for bees at the 
landscape level. This bi-stratified community presents intra- and interspecific temporal variation in phenodynamics, which combined, can provide a continuous supply for bees throughout the year, including during the dry season, when almost all plant species lose their leaves.

The importance of herbaceous and woody plants in the provision of pollen and nectar for bees has been previously highlighted (Rodarte et al. 2008, Quirino and Machado 2014, Pereira et al. 1989) for Caatinga vegetation, including for the same location studied here (Pereira et al. 1989). Although these studies had already emphasized the importance of floristic diversity and interspecific phenological differences in the supply of floral resources throughout the year, they missed important components for a complete approach on resources availability. They did not analyze the types of resources (i.e. pollen, nectar, extra floral resources) collected by bees, or their distribution in the vertical vegetation structure, neither how they vary over time, and their analysis was limited to a small number of individual per species, consequently, it was not possible to quantify the contribution of each species to the supply for bees.

Analyses at the community and landscape levels, like our study, show that woody plants with different growth forms (trees, shrubs, lianas) and herbaceous plant with different life forms (phanerophytes, chamaephytes, hemicryptophytes, and therophytes) are complementary in the supply of resources along the year. For example, we show that herbaceous plants supply goes from the beginning of the rainy season until the first months of the dry season (FebruaryAugust). However, hemicryptophytes, therophytes and chamaephytes herbs are the mainly source at different periods of this season, i.e., at the beginning, middle and final, respectively. Also, woody plants are important during the dry season (October-January), being this supply 
mainly provided by shrub and lianas. Additionally, we registered that the extrafloral resin supplies are related to trees with high abundance in the sampled plots $(C$. blanchetianus, $C$. bracteosum, and S. macrocarpa), which highlights the need to consider the provision of nonfloral resources for bees when analyzing plant communities. Therefore, our study reinforces the importance of phenological complementary in the design of conservation actions for bee populations as suggested by Timberlake et al (2019). However, our distinguished approach provided a better understanding of the complementarity of different vegetation strata in keeping resource availability for bees throughout seasons. That said, for more effective conservations actions we suggest to carefully consider life and growth forms of plant species for provide both vertical stratification and temporal availability of resources throughout the year.

For the herbaceous strata, it is worth mentioning that vegetation management actions should consider the reconciliation between bee conservation and productive activities like extensive cattle, sheep, and goat farming, that are very common in arid and semiarid regions like our study (Sampaio 1995). This is because extensive livestock farming prevents palatable herbaceous species (mainly therophytes) from completing their life cycle in the rainy season and, consequently, soil seed bank is not restored and the flora is not replenished in the following year (Mamede and Araújo 2008). Thus, such activities threat the resource supply provided by the herbaceous component (50\% therophytes life form), including oil-producing species like Angelonia sp. (Plantaginaceae). This plant species is one of main oil sources for bees of the genus Centris, key pollinators of wild and cultivated plants in the Caatinga (Aguiar et al. 2003). 
The cross-correlations analysis between phenological variables and abiotic factors (rainfall, soil moisture, and photoperiod) by life and growth forms allowed a more refined understanding of the relationship between water availability (rainfall and soil moisture), photoperiod and flowering patterns. As expected, we found significant correlations between rainfall and flowering patterns supporting previous studies in seasonally dry vegetation (e.g. Pereira et al. 1989, Machado et al. 1997, Borchert et al. 2004, McLaren and McDonald 2006, Amorim et al. 2009, Lima and Rodal 2010, Cortés-Flores et al. 2020), that found flowering of woody and herbaceous components positively correlating with rainfall, which is the main abiotic factor in short supply in these environments. However, by looking not only at rainfall but also at soil moisture, our analysis augmented previous evaluation, presenting a more general view of how water availability is related to plant's dynamics. Also, by building correlograms, we were able to jointly visualize the monthly variation of the different studied variables and pinpoint their time lags, an interesting data absent from previous studies. For example, water availability (resulted from the first rains at the beginning of the year) was significantly and positively correlated with the activity of lianas. This aligns with the fact that lianas in the Brazilian semi-arid have superficial roots and a highly efficient vascular system that quickly uses the water from the first rains and avoids subsequent competition with trees in the rainy season as demonstrated by Carvalho et al. (2016).

In turn, we found that the photoperiod decrease, observed from end of rainy to beginning of dry season (June to August), was positively correlated with flowering of herbaceous plants (chamaephytes and therophytes) and deciduous trees. Likewise, the photoperiod increase, observed from end of dry to beginning of rainy seasons (September to December), was related to the flowering of evergreen woody trees at the end of the dry season. These results follow similar findings observed in deciduous seasonal forests (Rivera and Borchert 2001, Borchert 
et al. 2004, and Cortés-Flores et al. 2020), and in the Caatinga (Lima and Rodal 2010). Also, it has been previously discussed (Rivera and Borchert 2001) that photoperiod control of flowering in tropical climate areas with prolonged and severe dry seasons, as in the Caatinga, represents an adaptive response to optimize reproduction, and it includes the induction of flowering when photoperiod decrease, leading into resource availability also in unfavorable times. Thus, our results also point out to the importance of implementing plant species with different responses to abiotic factors to ensure a continuous supply of resources for bees throughout the year.

The species A. cearensis, Cochlospermum vitifolium, Commiphora leptophloeos, Cynophalla flexuosa, Ziziphus joazeiro, and Handroanthus impetiginosus bear flowers in the dry season. Although they are not very abundant, the fact they bloom in the very dry season when most plants have lost their leaves makes them a treasurable resource and as their flowers stands out in the scarce vegetation, they are favored with a higher frequency of pollinator visits. Thus, they are "not to miss" candidates when planning plant implementations for bee maintenance. For example, $C$. vitifolium, whose flowers need vibration to release pollen, is among the most important pollinating plants for large bees, such as Xylocopa, which forage all year in the Caatinga (Roubik et al. 1982). Hence, it is imperative to include such species in a program for reforestation and restoration of degraded areas for bee conservation.

Despite the clear relationship between photoperiod and flowering in dry vegetations, such as in Caatinga, water availability (rainfall and soil moisture) is the determining factor of flowering, i.e., the ultimate cause (Borchert et al. 2004). Species that flower in the dry season also depend on the water stored in the root or stem system during the rainy season to produce flowers. Although expected, some woody species did not flower during our study timeframe. 
This was not because they have supra-annual flowering, but because of water shortage, as these species emit flowers annually under satisfactory water conditions. For example, $C$. leprosum and Libidibia férrea, showed an annual flowering pattern in phenological studies carried out during several years of regular rainfall as reported by two other Caatinga studies (Machado et al. 1997, Amorim et al. 2009). A long period of below-average rainfall (approximately six years of drought) preceded our study, and, as reported by Pereira et al. (1989), when there is not enough water availability, some species can go years without flowering. In a general context, the most profound implication of this is that the resource supply provided by these species is likely to disappear with global warming. A higher frequency of droughts and increased temperatures are predicted for the Brazilian semi-arid region (Marengo and Bernasconi 2015) as a result of climate change. Thus, C. leprosum, Libidibia férrea and other species will likely remain longer and longer without flowering, compromising the survival of bee species dependent on their floral supplies.

\section{The analysis of the resource availability in the vertical structure of the bi-stratified plant} community (herbaceous and woody) and their temporal distribution in seasonally dry environments demonstrates that in the rainy and dry seasons, both strata are important for bee conservation as they differ in resource supply. In summary, in the planning and implementation of management actions for the reforestation and restoration of degraded areas to mitigate current scenario and future climate change effects associated with bee conservation (less water availability, less flowering, less resources acquisition), it is necessary to consider the floral phenodynamics variation in the vertical vegetation structure and the temporal distribution of flowering to provide the most significant possible supply of resources for feeding (pollen, nectar, and oils) and nest-building (resins). 


\section{Acknowledgments}

We thank the Agricultural Sciences Center of the Federal University of Ceará for facilitating hosting, transportation, and logistical support at the Vale do Curu Experimental Farm under its administration. We also thank Bruno Menezes and Waldir Mantovani for their help in identifying the plants.

\section{Declarations}

Funding: This study was financed in part by the Coordenação de Aperfeiçoamento de Pessoal de Nível Superior - Brasil (CAPES) - Finance Code 001. The Program for Education and Training (PAEC) of the Organization of American States (OAS) and the Coimbra Group of Brazilian Universities (GCUB) granted FJC a Doctoral scholarship. The Brazilian National Council for Scientific and Technological Development (CNPq) granted BMF a research productivity fellowship (\#305126/2013-0). The Coordenação de Aperfeiçoamento de Pessoal de Nível Superior - Brasil (CAPES) granted CMAF a Post-doctoral fellowship (Finance Code 001).

Conflicts of interest/Competing interests: We do not have competing interests or conflicts of interest.

Ethics approval: Not applicable

Consent to participate: Not applicable

Consent for publication: Not applicable

Availability of data and material: the data supporting this study can be found in 10.6084/m9.figshare.13148765.

Code availability: Not applicable 


\section{References}

Aguiar CML, Santos GM de M, Martins CF, Presley SJ (2013) Trophic niche breadth and niche overlap in a guild of flower-visiting bees in a Brazilian dry forest. Apidologie 44:153-162 doi:10.1007/s13592-012-0167-4

Aguiar CML, Zanella FCV, Martins CF, Carvalho CAL de (2003) Plantas visitadas por Centris spp. (Hymenoptera: Apidae) na Caatinga para obtenção de recursos florais. Neotrop Entomol 32:247-259 doi:10.1590/S1519-566X2003000200009

Aleixo KP, de Faria LB, Groppo M, et al (2014) Spatiotemporal distribution of floral resources in a Brazilian city: Implications for the maintenance of pollinators, especially bees. Urban Forestry \& Urban Greening 13:689-696 doi: 10.1016/j.ufug.2014.08.002

Alvares CA, Stape JL, Sentelhas PC, et al (2013) Köppen's climate classification map for Brazil. metz 22:711-728 doi: 10.1127/0941-2948/2013/0507

Amorim IL de, Sampaio EV de SB, Araújo E de L (2009) Fenologia de espécies lenhosas da caatinga do Seridó, RN. Rev Árvore 33:491-499 doi: 10.1590/S010067622009000300011

Andrade-Lima D (1981) The caatingas dominium. Revista Brasileira de Botânica 4:149-153

Borchers HW (2019) Pracma: Practical Numerical Math Functions, R Package. Version 2.2.9URL https://cran.r-project.org/web/packages/pracma/index.html

Borchert R, Meyer SA, Felger RS, Porter-Bolland L (2004) Environmental control of flowering periodicity in Costa Rican and Mexican tropical dry forests. Global Ecology and Biogeography 13:409-425. https://doi.org/10.1111/j.1466-822X.2004.00111.X

Brasil-Ministério de Integração Nacional (2018) Delimitação do semiárido. http://www.sudene.gov.br/delimitacao-do-semiarido. Accessed 30 Aug 2020 
Carvalho ECD, Martins FR, Oliveira RS, et al (2016) Why is liana abundance low in semiarid climates? Austral Ecology 41:559-571 doi: 10.1111/aec.12345

Cortés-Flores J, Hernández-Esquivel KB, González-Rodríguez A, Ibarra-Manríquez G (2017) Flowering phenology, growth forms, and pollination syndromes in tropical dry forest species: Influence of phylogeny and abiotic factors. Am J Bot 104:39-49 doi: 10.3732/ajb.1600305

Costa RC, Araújo FS, Lima-Verde LW (2007) Flora and life-form spectrum in an area of deciduous thorn woodland (caatinga) in northeastern, Brazil. Journal of Arid Environments 68:237-247 doi: 10.1016/j.jaridenv.2006.06.003

Daubenmire RF (1959) Canopy coverage method of vegetation analysis. Northwest Science $33: 43-64$

Donkersley P (2019) Trees for bees. Agriculture, Ecosystems \& Environment 270-271:79-83 doi:10.1016/j.agee.2018.10.024

Forrest J, Miller-Rushing AJ (2010) Toward a synthetic understanding of the role of phenology in ecology and evolution. Phil Trans R Soc B 365:3101-3112 doi: 10.1098/rstb.2010.0145

Fournier LA (1974) Un método cuantitativo para la medición de características fenológicas en árboles. Turrialba 24:422-423

Gardner AS, Maclean IMD, Gaston KJ (2020) A new system to classify global climate zones based on plant physiology and using high temporal resolution climate data. J Biogeogr jbi.13927 doi: 10.1111/jbi.13927

Garratt MPD, Senapathi D, Coston DJ, et al (2017) The benefits of hedgerows for pollinators and natural enemies depends on hedge quality and landscape context. Agriculture, Ecosystems \& Environment 247:363-370 doi: 10.1016/j.agee.2017.06.048 
Goulson D, Nicholls E, Botias C, Rotheray EL (2015) Bee declines driven by combined stress from parasites, pesticides, and lack of flowers. Science 347:1255957-1255957 doi: 10.1126/science. 1255957

Greenleaf SS, Williams NM, Winfree R, Kremen C (2007) Bee foraging ranges and their relationship to body size. Oecologia 153:589-596 doi: 10.1007/s00442-007-0752-9

IPBES (2016) The assessment report of the Intergovernmental Science-Policy Platform on Biodiversity and Ecosystem Services on pollinators, pollination and food production. Potts SG, Imperatriz-Fonseca VL, Ngo HT (eds). Secretariat of the Intergovernmental Science-Policy Platform on Biodiversity and Ecosystem Services, Bonn, Germany. IPCC (2014) Climate Change 2014: Synthesis Report. Contribution of Working Groups I, II and III to the Fifth Assessment Report of the Intergovernmental Panel on Climate Change. Core Writing Team, Pachauri RK, Meyer LA(eds.). IPCC, Geneva, Switzerland

Klein A-M, Vaissière BE, Cane JH, et al (2007) Importance of pollinators in changing landscapes for world crops. Proc R Soc B 274:303-313 doi: 10.1098/rspb.2006.3721

Lawson DA, Rands SA (2019) The effects of rainfall on plant-pollinator interactions. Arthropod-Plant Interactions 13:561-569 doi: 10.1007/s11829-019-09686-z

Legendre P, Legendre L (2012) Numerical ecology, 3rd ed. Elsevier, Amsterdam

Lima ALA, Rodal MJN (2010) Phenology and wood density of plants growing in the semiarid region of northeastern Brazil. Journal of Arid Environments 74:1363-1373 doi: 10.1016/j.jaridenv.2010.05.009

Machado IC, Lopes AV (2004) Floral Traits and Pollination Systems in the Caatinga, a Brazilian Tropical Dry Forest. Annals of Botany 94:365-376 doi: 10.1093/aob/mch152 
670

671

672

673

674

675

676

677

678

679

680

681

682

683

684

685

686

687

688

689

690

691

692

Machado ICS, Barros LM, Sampaio EVSB (1997) Phenology of Caatinga Species at Serra Talhada, PE, Northeastern Brazil. Biotropica 29:57-68 doi: 10.1111/j.17447429.1997.tb00006.x

Mamede M de A, de Araújo FS (2008) Effects of slash and burn practices on a soil seed bank of caatinga vegetation in Northeastern Brazil. Journal of Arid Environments 72:458470 doi: 10.1016/j.jaridenv.2007.07.014

Marengo JA, Bernasconi M (2015) Regional differences in aridity/drought conditions over Northeast Brazil: present state and future projections. Climatic Change 129:103-115 doi: 10.1007/s10584-014-1310-1

McLaren KP, McDonald MA (2005) Seasonal Patterns of Flowering and Fruiting in a Dry Tropical Forest in Jamaica1. Biotropica 37:584-590 doi: 10.1111/j.17447429.2005.00075.x

Michener CD (2007) The Bees of the World, 2nd ed. Johns Hopkins University Press, Baltimore, Maryland

Monasterio M, Sarmiento G (1976) Phenological Strategies of Plant Species in the Tropical Savanna and the Semi-Deciduous Forest of the Venezuelan Llanos. Journal of Biogeography 3:325 doi.org/10.2307/3037976

Morellato LPC, Alberton B, Alvarado ST, et al (2016) Linking plant phenology to conservation biology. Biological Conservation 195:60-72 doi: 10.1016/j.biocon.2015.12.033

Moro MF, Macedo MB, Moura-Fé MM de, et al (2015) Vegetação, unidades fitoecológicas e diversidade paisagística do estado do Ceará. Rodriguésia 66:717-743 doi:

$10.1590 / 2175-7860201566305$ 
693

694

695

696

697

698

699

700

701

702

703

704

705

706

707

708

709

710

711

712

713

714

715

716

717

Moro MF, Nic Lughadha E, de Araújo FS, Martins FR (2016) A Phytogeographical Metaanalysis of the Semiarid Caatinga Domain in Brazil. The Botanical Review 82:91-148 doi: 10.1007/s12229-016-9164-Z

Nagahama A, Yahara T (2019) Quantitative comparison of flowering phenology traits among trees, perennial herbs, and annuals in a temperate plant community. Am J Bot 106:1545-1557 doi: 10.1002/ajb2.1387

Ogilvie JE, Forrest JR (2017) Interactions between bee foraging and floral resource phenology shape bee populations and communities. Current Opinion in Insect Science 21:75-82 doi: 10.1016/j.cois.2017.05.015

Ogilvie JE, Griffin SR, Gezon ZJ, et al (2017) Interannual bumble bee abundance is driven by indirect climate effects on floral resource phenology. Ecol Lett 20:1507-1515 doi: 10.1111/ele. 12854

Ollerton J, Winfree R, Tarrant S (2011) How many flowering plants are pollinated by animals? Oikos 120:321-326 doi: 10.1111/j.1600-0706.2010.18644.x

Pereira R, Araújo J, Lima R, et al (1989) Estudos fenológicos de algumas espécies lenhosas e herbáceas da caatinga. Revista Ciência Agronômica 20:11-20

Potts SG, Biesmeijer JC, Kremen C, et al (2010) Global pollinator declines: trends, impacts and drivers. Trends in Ecology \& Evolution 25:345-353 doi:

10.1016/j.tree.2010.01.007

Quirino Z, Machado I (2014) Pollination syndromes in a Caatinga plant community in northeastern Brazil: seasonal availability of floral resources in different plant growth habits. Brazilian Journal of Biology 74:62-71 doi: 10.1590/1519-6984.17212

R Core Team (2019) R: A language and environment for statistical computing. Version 3.5.3. R Foundation for Statistical Computing, Vienna, Austria. URL https://www.Rproject.org/ 
Raunkiær C (1934) Life forms of plants and statistical plant geography. Oxford, The Clarendon Press

Requier F, Leonhardt SD (2020) Beyond flowers: including non-floral resources in bee conservation schemes. J Insect Conserv 24:5-16 doi: 10.1007/s10841-019-00206-1

Rivera G, Borchert R (2001) Induction of flowering in tropical trees by a 30-min reduction in photoperiod: evidence from field observations and herbarium specimens. Tree Physiol 21:201-212 doi: 10.1093/treephys/21.4.201

Rodarte ATA, Silva FO da, Viana BF (2008) A flora melitófila de uma área de dunas com vegetação de caatinga, Estado da Bahia, Nordeste do Brasil. Acta Bot Bras 22:301312 doi: 10.1590/S0102-33062008000200001

Roubik DW (1989) Ecology and Natural History of Tropical Bees. Cambridge University Press

Roubik DW, Ackerman JD, Copenhaver C, Smith BH (1982) Stratum, Tree, and Flower Selection by Tropical Bees: Implications for the Reproductive Biology of Outcrossing Cochlospermum Vitifolium in Panama. Ecology 63:712-720 doi: 10.2307/1936792

Roulston TH, Goodell K (2011) The Role of Resources and Risks in Regulating Wild Bee Populations. Annual Review of Entomology 56:293-312 doi: 10.1146/annurev-ento120709-144802

Sampaio E (1995) Overview of the Brazilian caatinga. In: Bullock SH, Mooney HA, Medina E (eds) Seasonally dry tropical forests. Cambridge University Press, Cambridge; New York, NY, USA, pp 35-63

Silva JLS e, Cruz-Neto O, Peres CA, et al (2019) Climate change will reduce suitable Caatinga dry forest habitat for endemic plants with disproportionate impacts on specialized reproductive strategies. PLoS ONE 14:e0217028 doi:

10.1371/journal.pone.0217028 
Souza MJN de, Oliveira JGB de, Lins RC, Jatobá L (1992) Condições geo-ambientais do semi-árido brasileiro. CI \& Trop. 20: 173-198

Timberlake TP, Vaughan IP, Memmott J (2019) Phenology of farmland floral resources reveals seasonal gaps in nectar availability for bumblebees. J Appl Ecol 56:1585-1596 doi: $10.1111 / 1365-2664.13403$

Venjakob C, Klein A-M, Ebeling A, et al (2016) Plant diversity increases spatio-temporal niche complementarity in plant-pollinator interactions. Ecol Evol 6:2249-2261 doi: $10.1002 /$ ece 3.2026

Wagner DL (2020) Insect Declines in the Anthropocene. Annu Rev Entomol 65:457-480 doi: 10.1146/annurev-ento-011019-025151

Whittaker RH (1975) Communities and ecosystems. Macmillan, New York 
Figure 1. Climatic characterization, photoperiod, and water availability in the soil in a

771

Tropical Savanna (Caatinga) area in northeastern Brazil. A) Walter-Lieth climate diagram comprising the three years of the study (2017-2019). B) Monthly photoperiod. C) Monthly soil moisture in relation to the monthly accumulated rainfall. The blue line represents the mean of the three plots, and the value of each plot represents the mean of ten soil samples. D) Cross-correlation between soil moisture and rainfall confirming the initial lag in soil moisture in relation to rainfall (significant correlations above the dashed line on the negative side of the $\mathrm{x}$-axis) and subsequent maintenance of water availability (significant correlations at zero and on the positive side).

Figure 2. Composition of plant species visited by bees, classified by type of assemblage, growth form, life form, and resource available in a Tropical Savanna (Caatinga) area in northeastern Brazil. The values represent the total mean of the proportion found in the three plots. Figure S4 shows the individual data per plot.

Figure 3. Phenodynamics of the plant community visited by bees and classified by the type of floral resource (nectar and pollen) according to life forms in a Tropical Savanna (Caatinga) area in northeastern Brazil. The left side represents species activity (percentage of species bearing flowers), and the right side, flowering intensity (percentage of the canopy with woody individuals bearing flowers of all flowering species and percentage of soil cover with herbaceous plants bearing flowers). The shaded areas in the background represent monthly accumulated rainfall and soil moisture. 
793 Figure 4. Phenodynamics of the plant community visited by bees and classified by the type of

794 floral resource (nectar and pollen) according to growth forms in a Tropical Savanna

795 (Caatinga) area in northeastern Brazil. The left side represents species activity (percentage of

796 species bearing flowers), and the right side, flowering intensity (percentage of the canopy

797 with woody individuals bearing flowers of all flowering species and percentage of soil cover

798 with herbaceous plants bearing flowers). The shaded areas in the background represent

799 monthly accumulated rainfall and soil moisture.

800

801 Figure 5. Cross-correlations between phenodynamics (species activity and flowering

802 intensity) of plants visited by bees and abiotic factors (rainfall, soil moisture, and

803 photoperiod) in a Tropical Savanna (Caatinga) area in northeastern Brazil, according to life

804 and growth forms. Significant correlations (bars above the dashed line) on the negative side of

805 the $\mathrm{x}$-axis indicate the lag in months in variables' responses to the abiotic factor. Significant

806 correlations on the positive side of the $\mathrm{x}$-axis indicate that the phenological event preceded the

807 abiotic factor. Correlation at zero lag indicates a response in the same month of the change in

808 the abiotic factor 
Figure 1

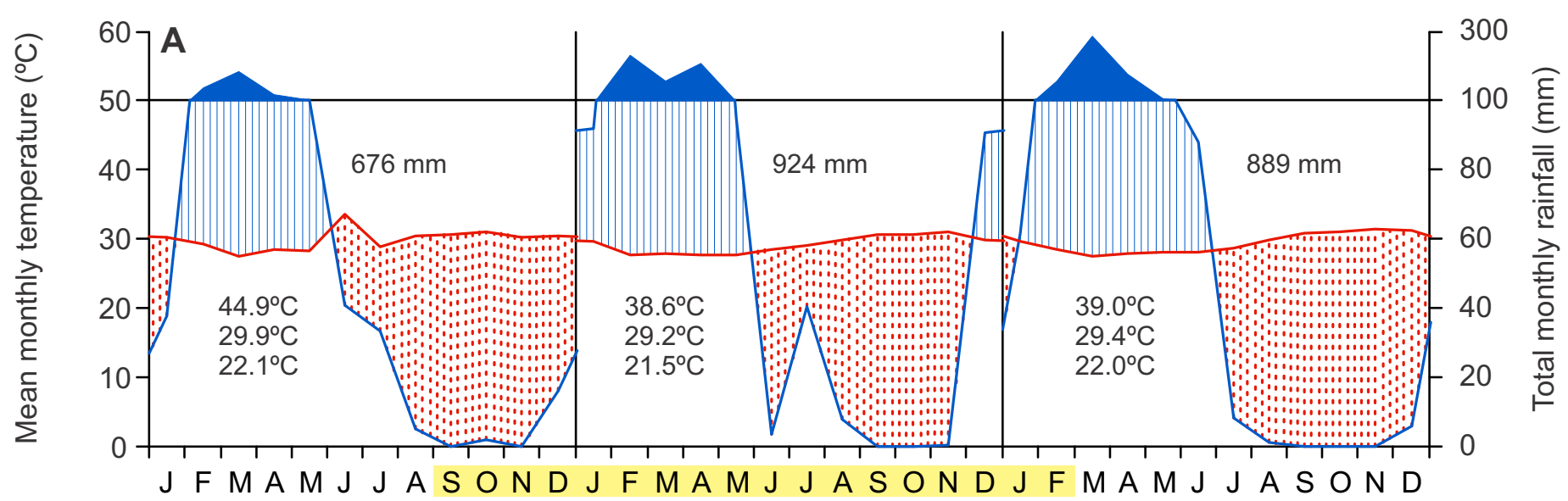

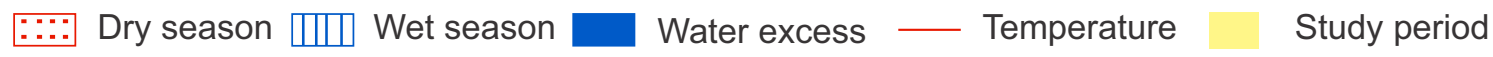

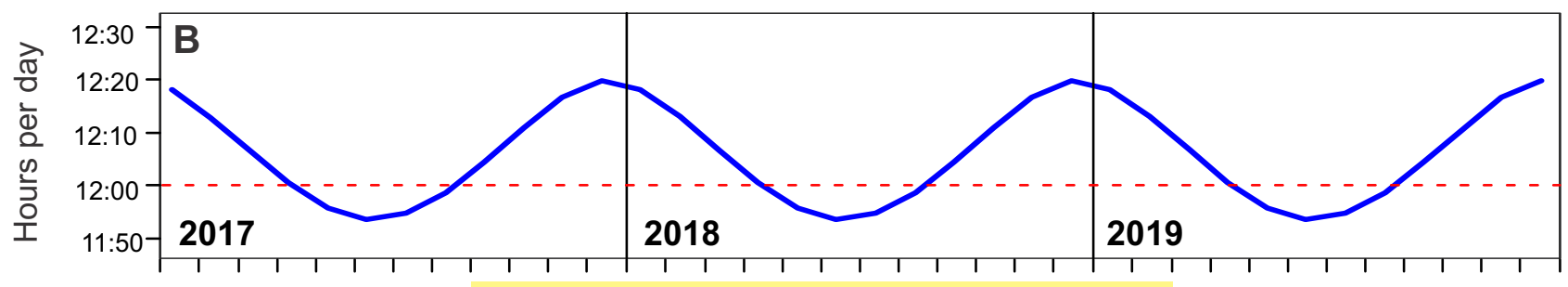

J FMAMJJASONDJFMAMJJASONDJFMAMJJASOND
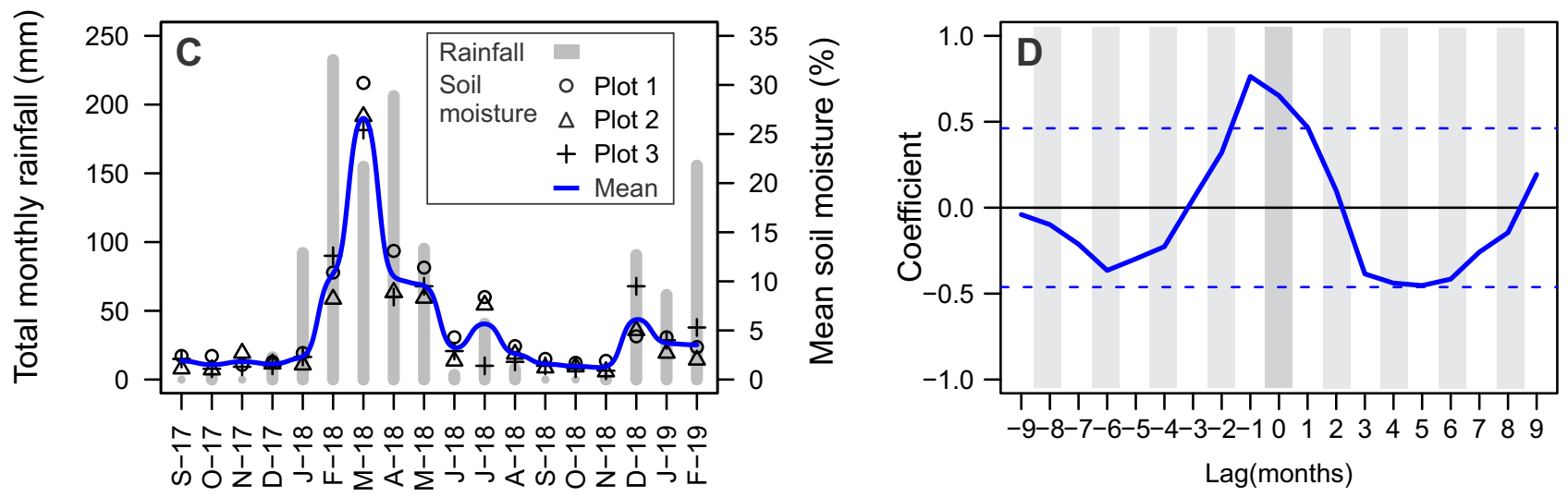
Figure 2

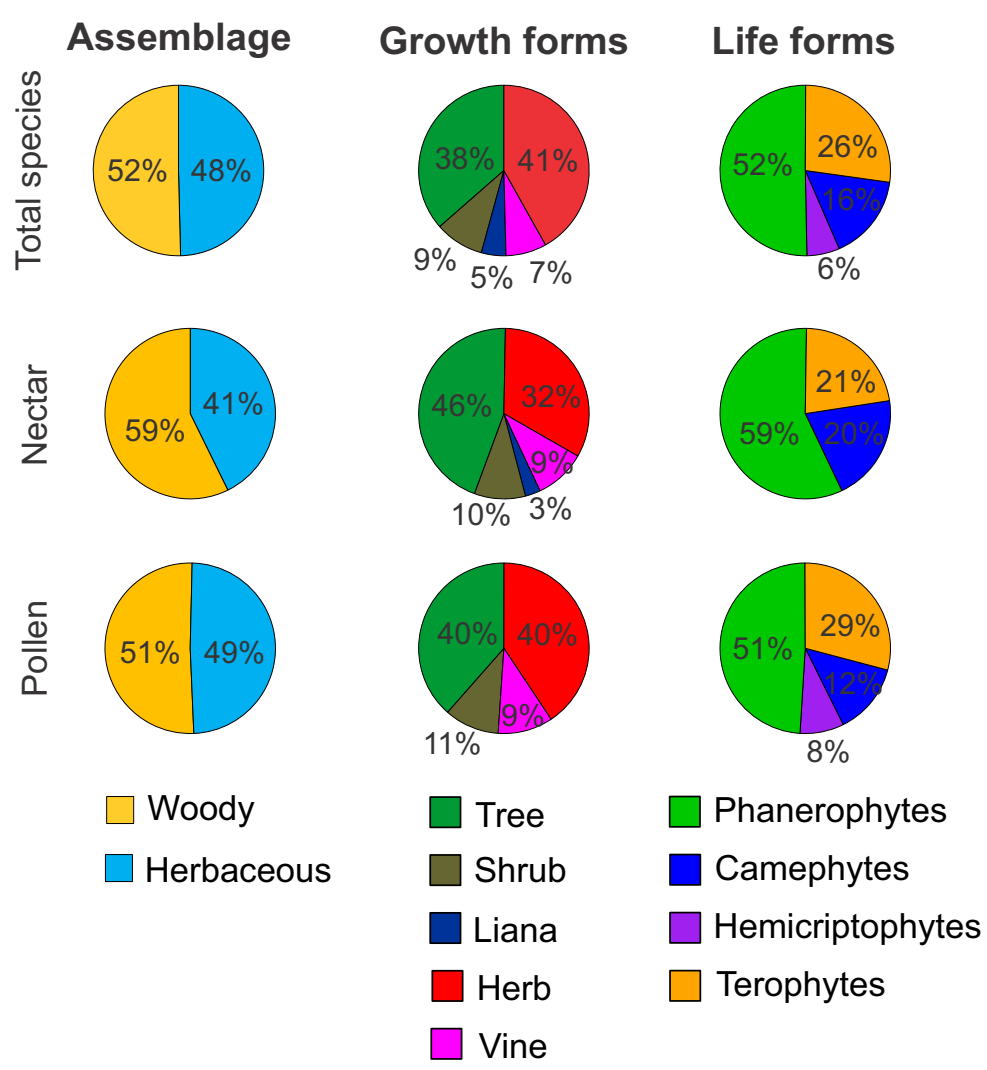


Figure 3

\section{Species activity}
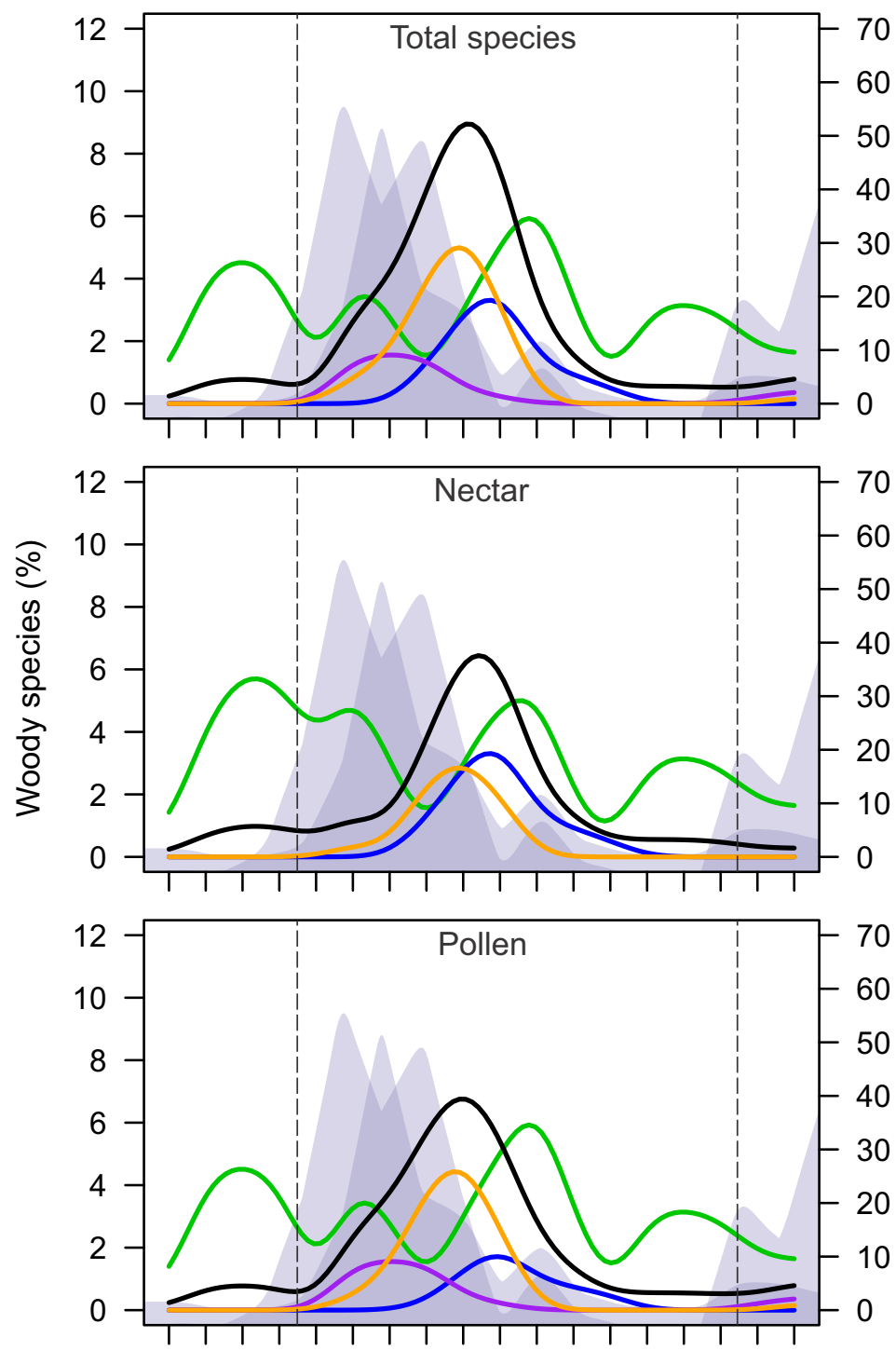

ง

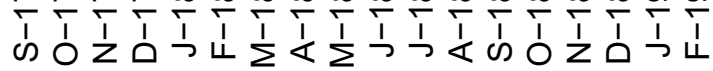

$$
\begin{array}{ll} 
& - \text { Phanerophytes }- \text { Hemicriptophytes } \\
& - \text { Cammunity } \quad-\text { Terophytes }
\end{array}
$$

Flowering Intensity
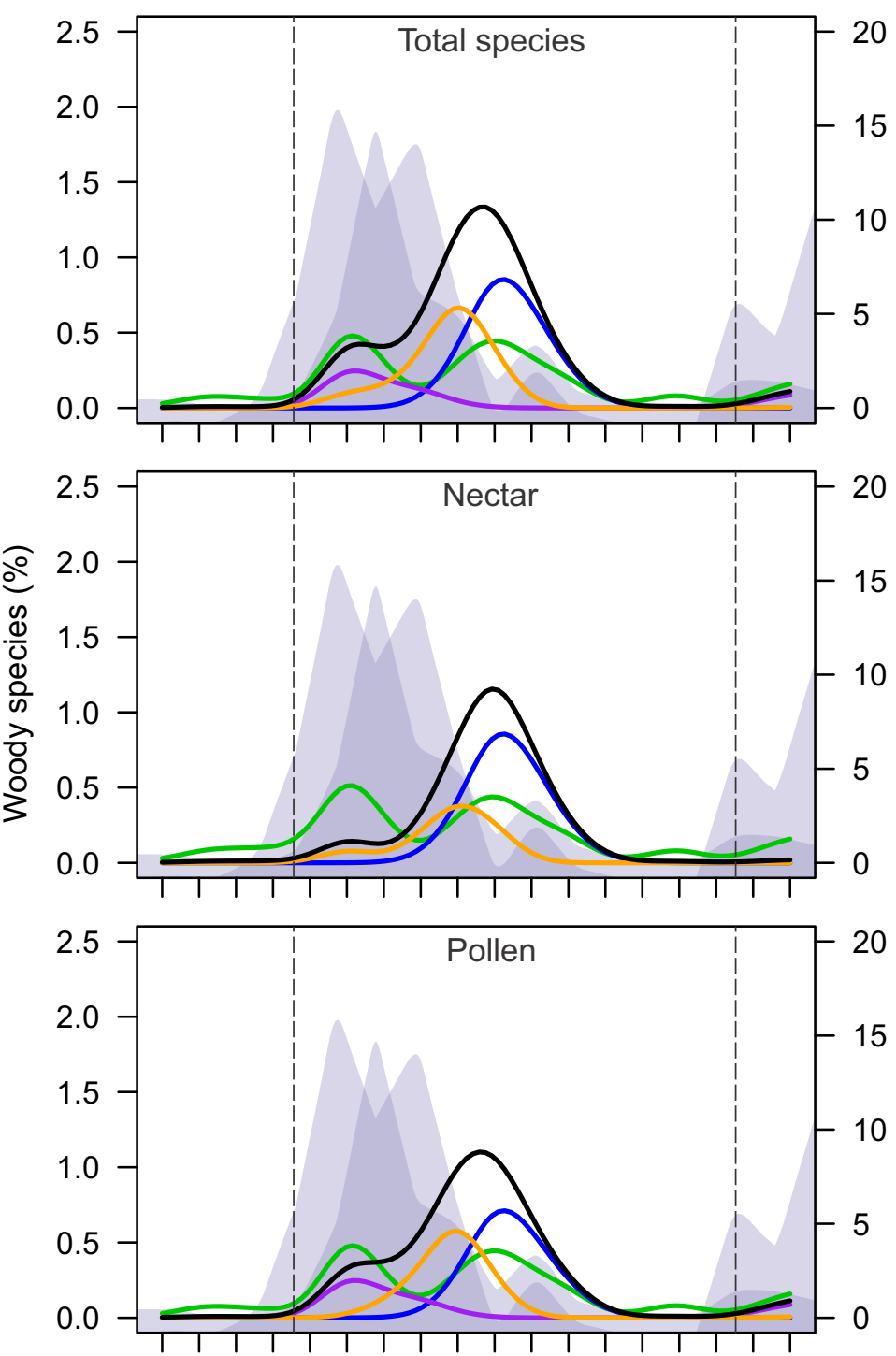

ヘ

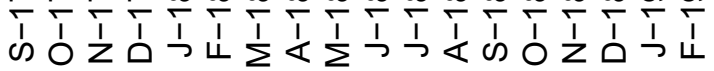

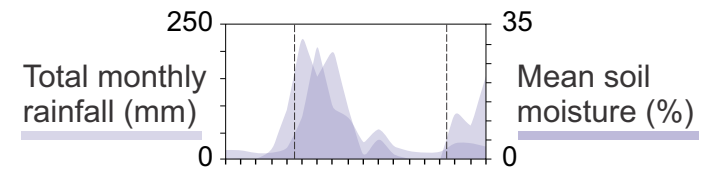


Figure 4

\section{Species activity}
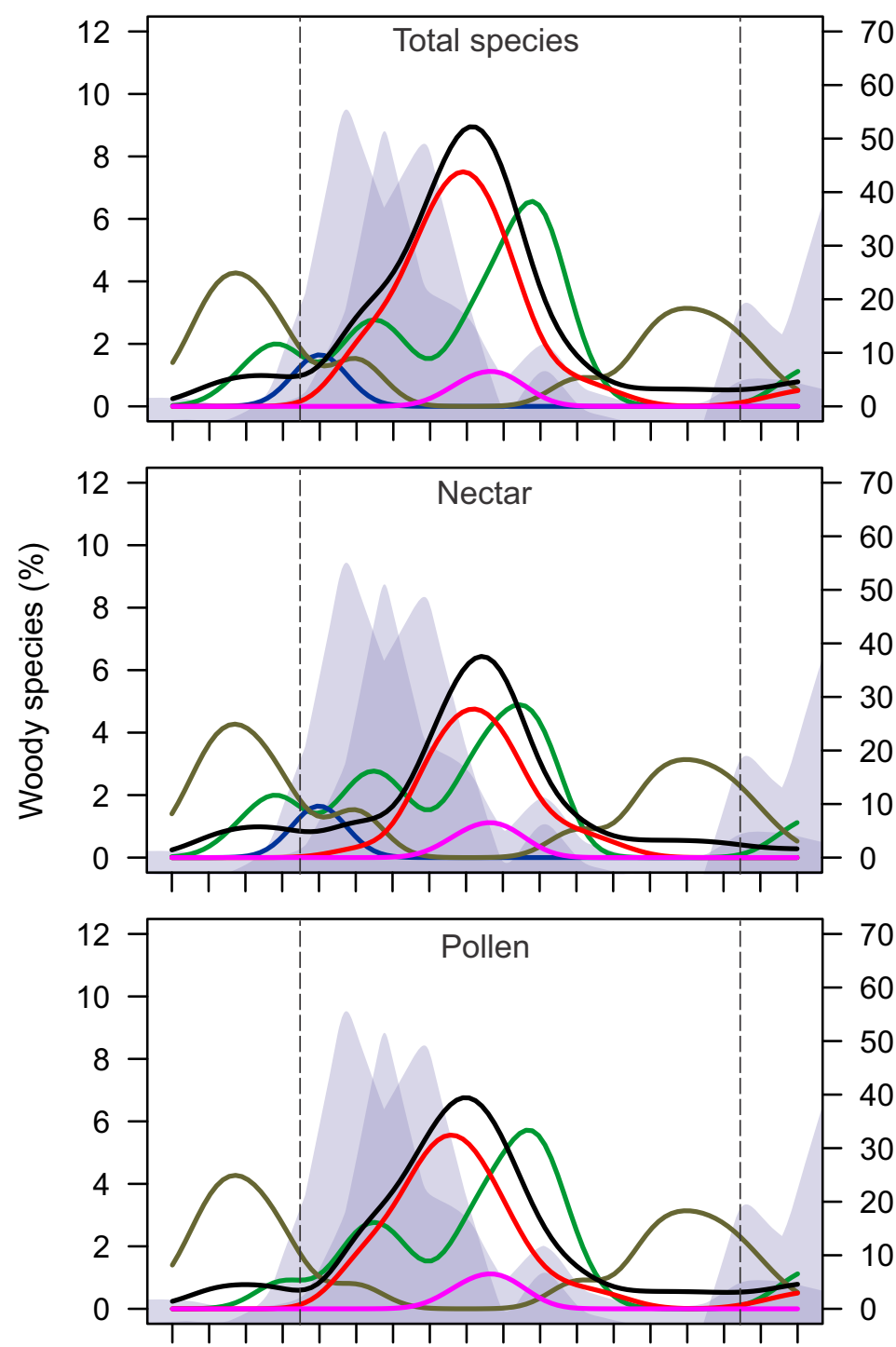

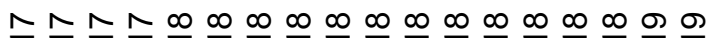

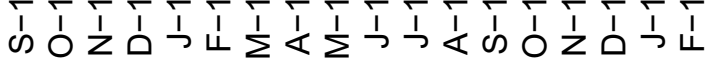

- Community
Flowering Intensity
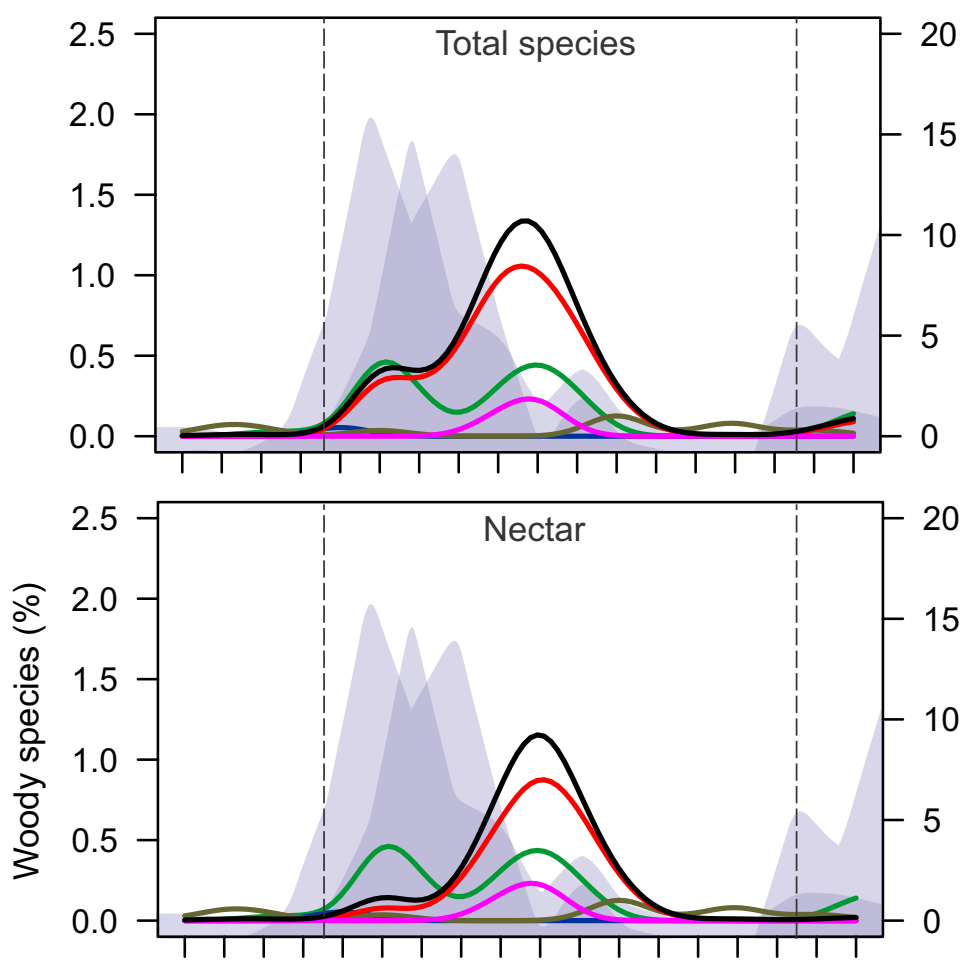

$\widehat{0}$
0
0
0
0
0
0
0
0
0
0
$d$
0
0
$\frac{0}{0}$
$\frac{0}{1}$
I

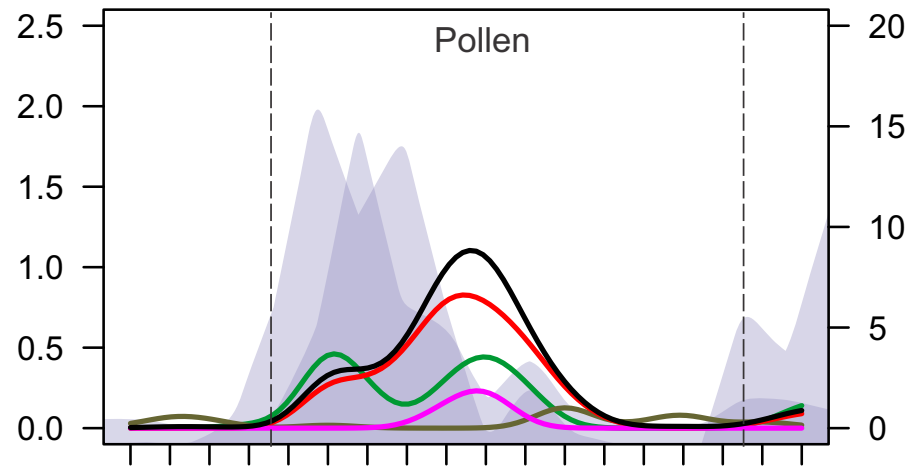

ㅅำำ $\infty \infty \infty \infty \infty \infty \infty \infty \infty \infty \infty \circ \infty$

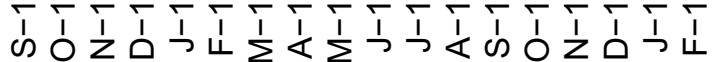

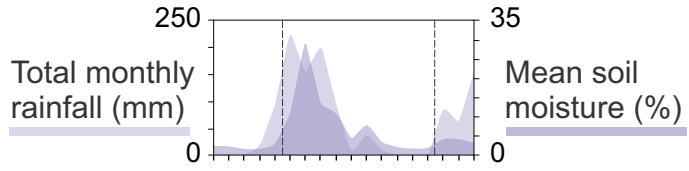


Figure 5
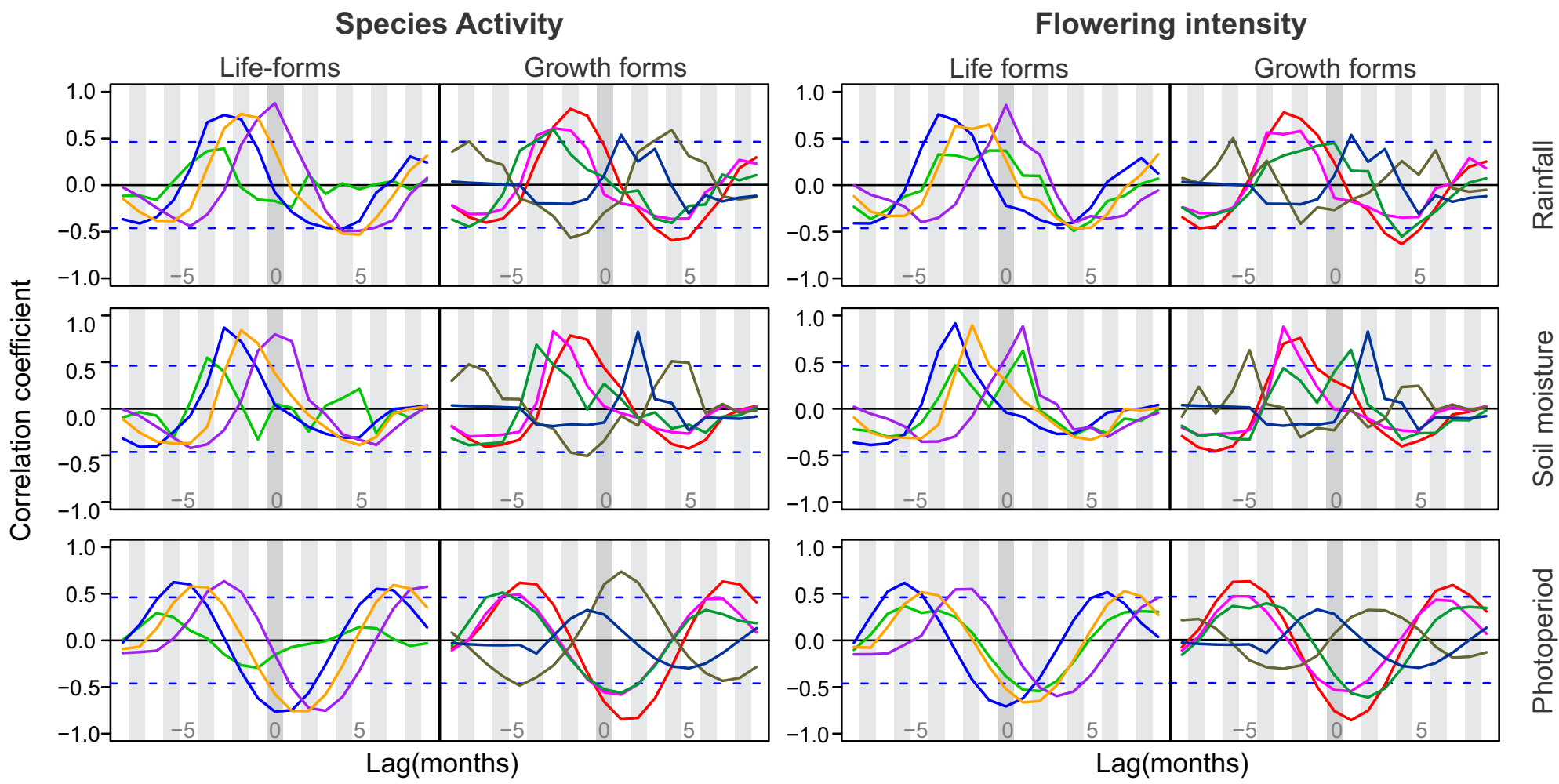

Life-forms: - Phanerophytes - Camephytes - Hemicriptophytes - Terophytes

Growth forms: - Tree - Shrub - Liana - Herb - Vine 


\section{Figures}

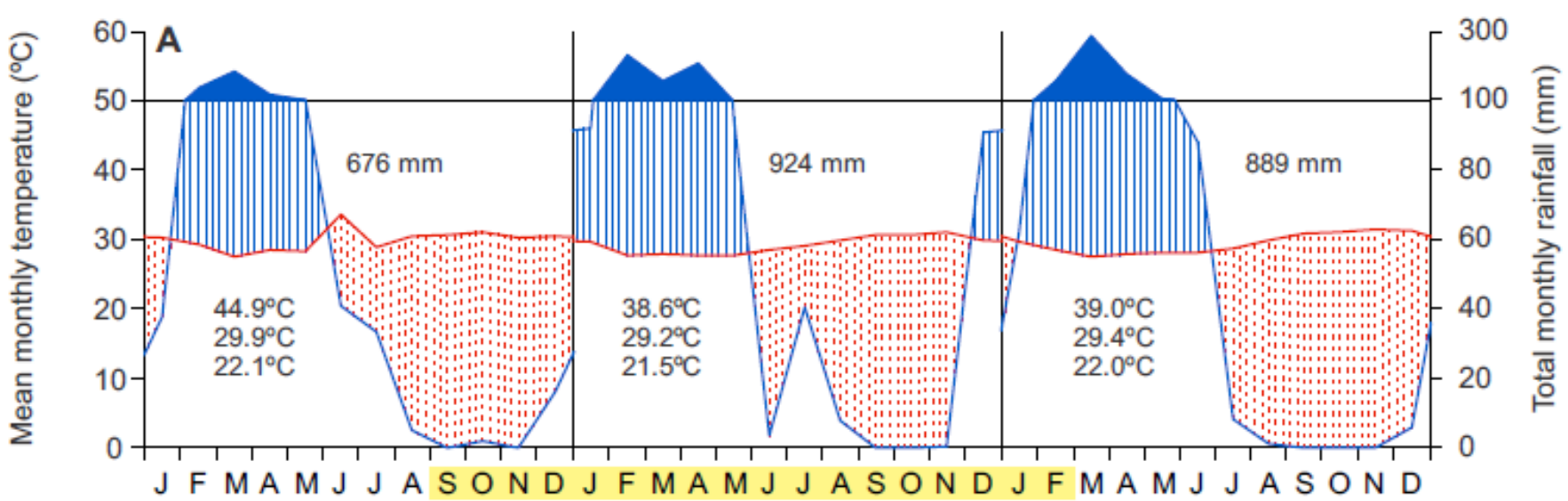

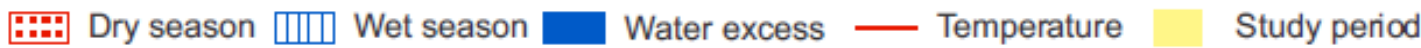

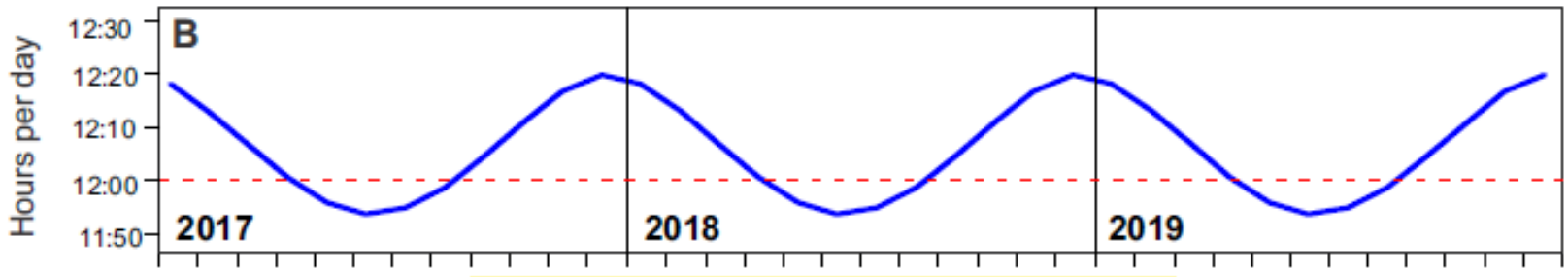

J F MAMJJASONDJFMAMJJASONDJFMAMJ JASOND
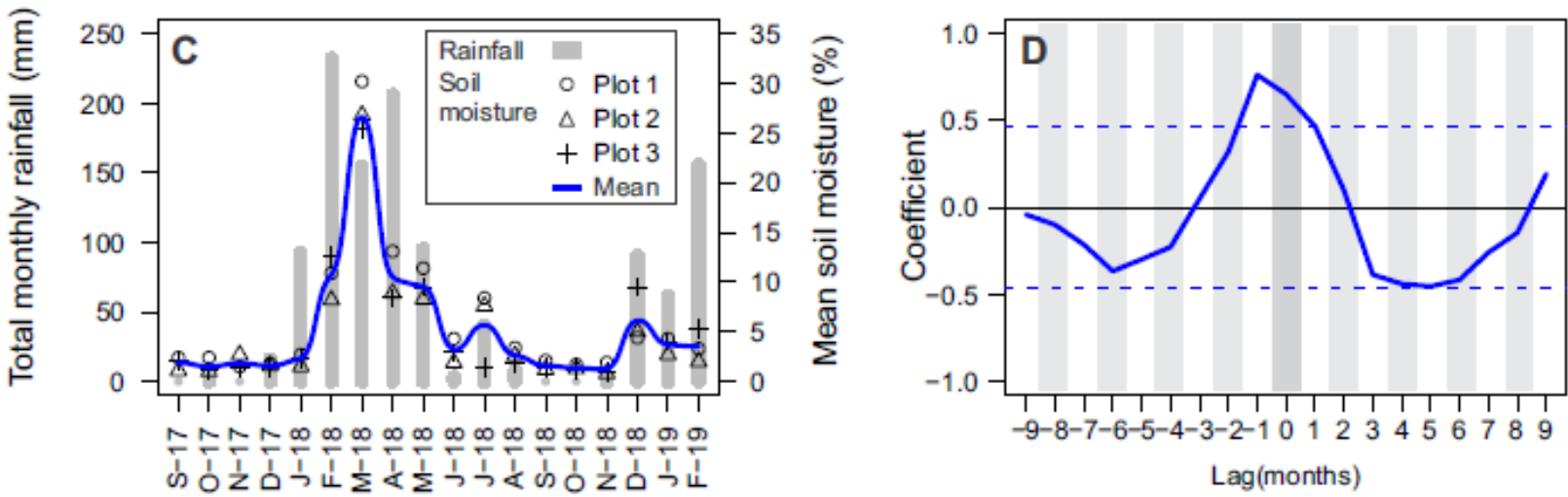

\section{Figure 1}

Climatic characterization, photoperiod, and water availability in the soil in a Tropical Savanna (Caatinga) area in northeastern Brazil. A) Walter-Lieth climate diagram comprising the three years of the study (2017-2019). B) Monthly photoperiod. C) Monthly soil moisture in relation to the monthly accumulated rainfall. The blue line represents the mean of the three plots, and the value of each plot represents the mean of ten soil samples. D) Cross-correlation between soil moisture and rainfall confirming the initial lag in soil moisture in relation to rainfall (significant correlations above the dashed line on the negative side of the $x$-axis) and subsequent maintenance of water availability (significant correlations at zero and on the positive side). 


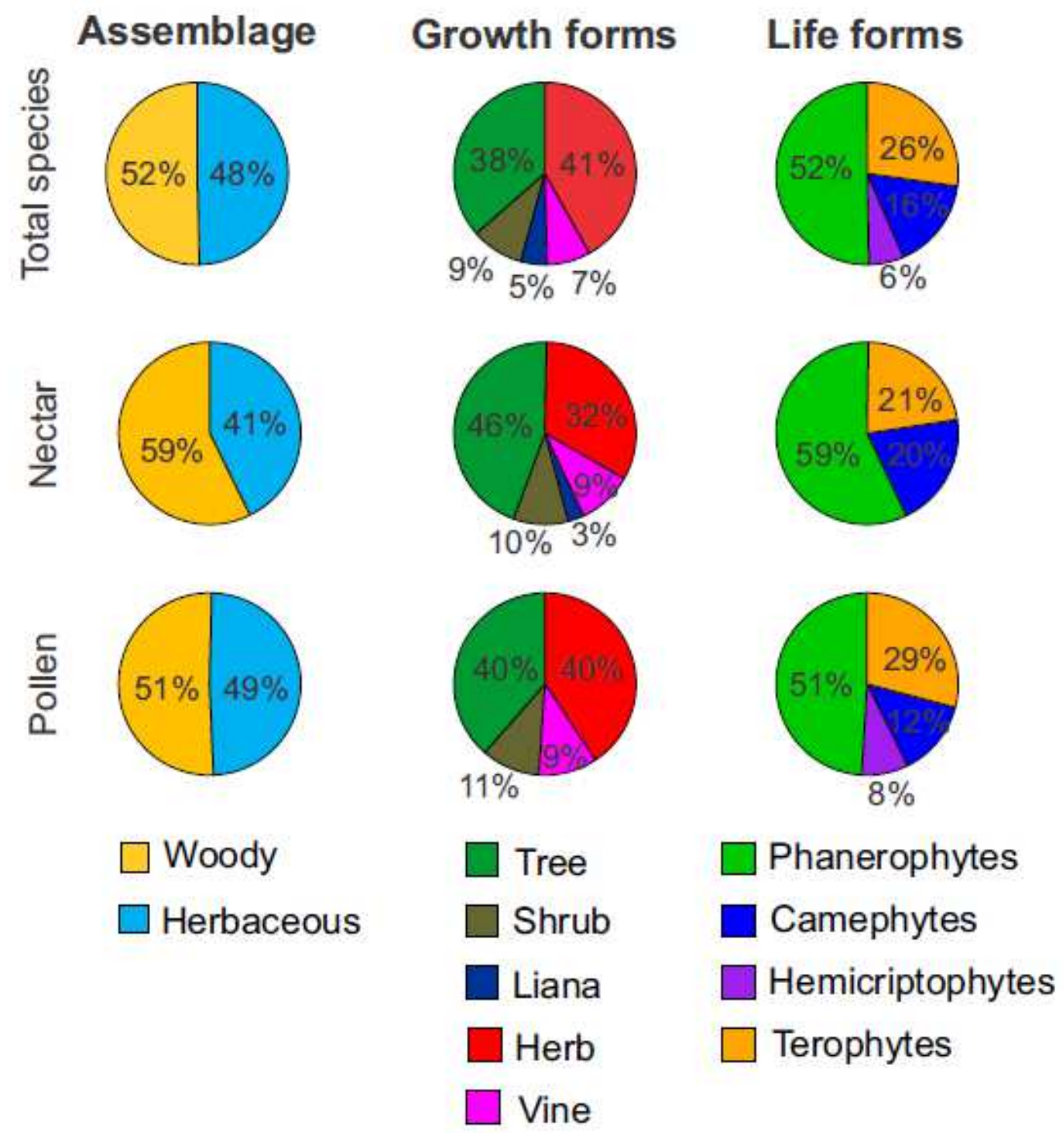

Figure 2

Composition of plant species visited by bees, classified by type of assemblage, growth form, life form, and resource available in a Tropical Savanna (Caatinga) area in northeastern Brazil. The values represent the total mean of the proportion found in the three plots. Figure $S 4$ shows the individual data per plot. 
Species activity
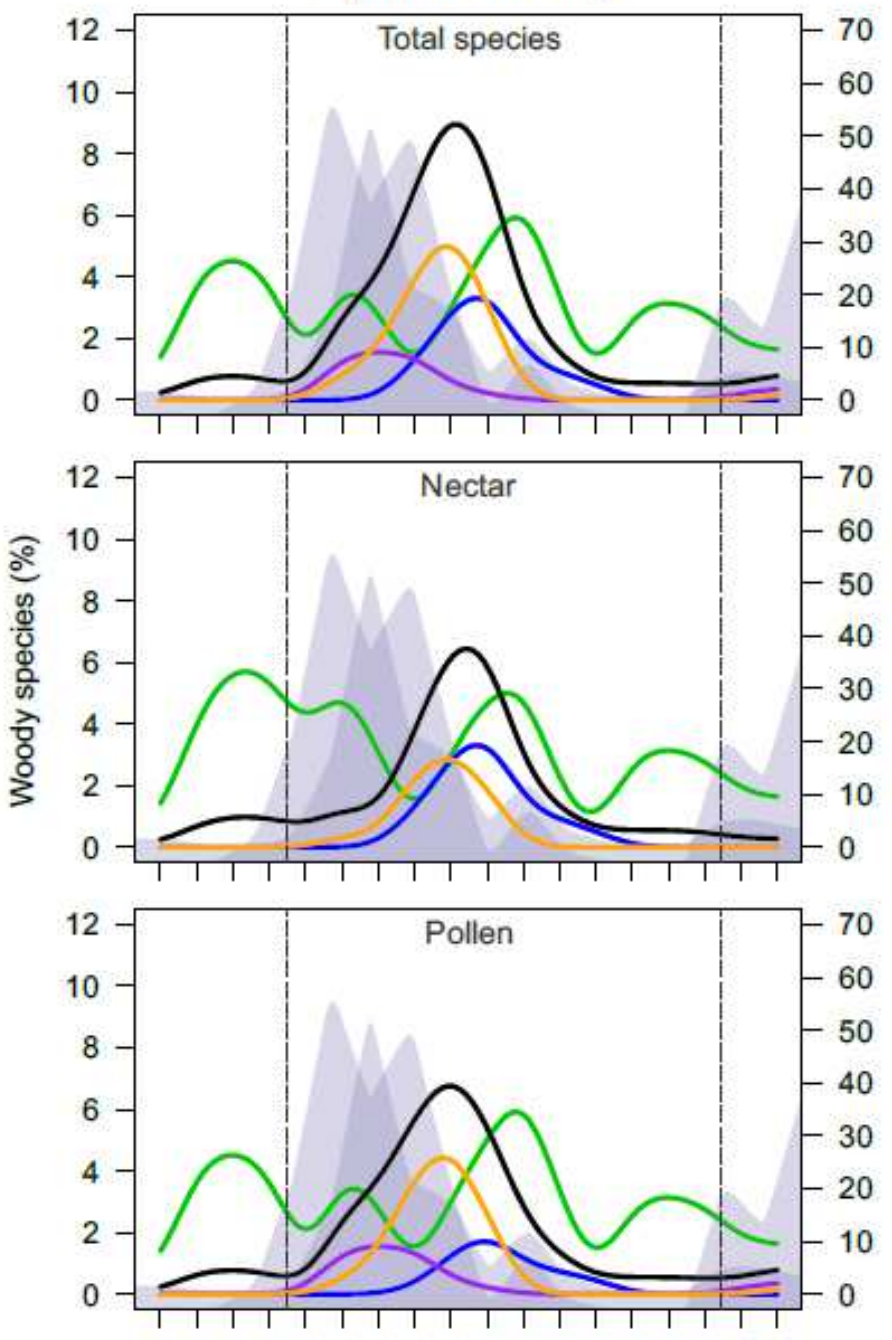

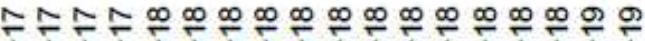

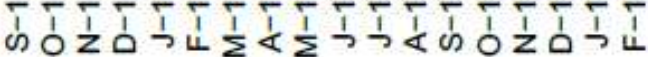

$$
\begin{array}{ll}
\text { - Community } & \text { - Phanerophytes }- \text { Hemicriptophytes } \\
& - \text { Camephytes }- \text { Terophytes }
\end{array}
$$

Flowering Intensity
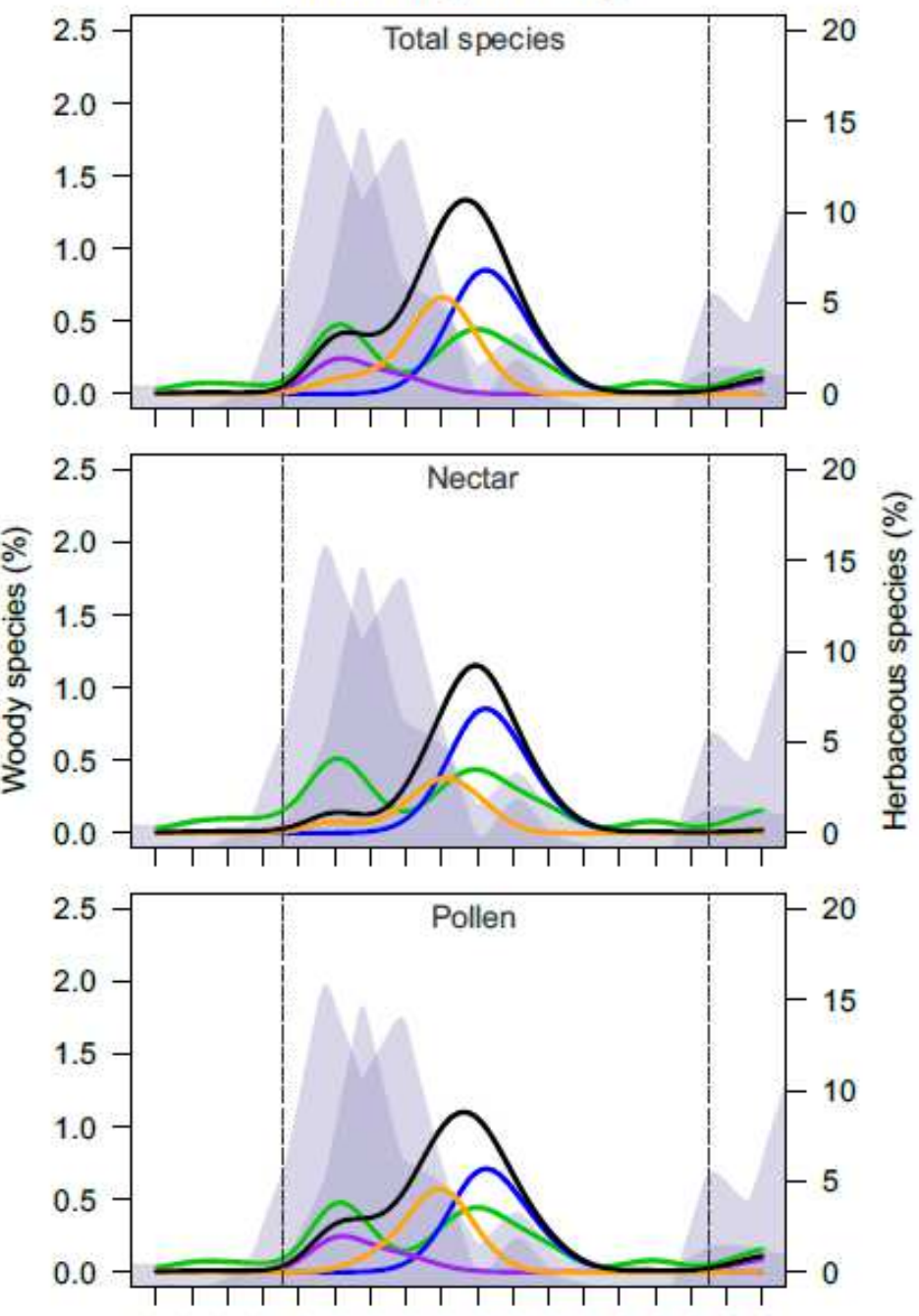

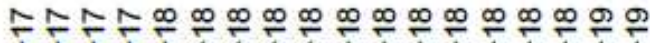

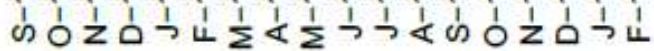

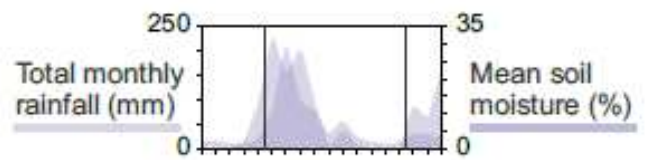

\section{Figure 3}

Phenodynamics of the plant community visited by bees and classified by the type of floral resource (nectar and pollen) according to life forms in a Tropical Savanna (Caatinga) area in northeastern Brazil. The left side represents species activity (percentage of species bearing flowers), and the right side, flowering intensity (percentage of the canopy with woody individuals bearing flowers of all flowering species and percentage of soil cover with herbaceous plants bearing flowers). The shaded areas in the background represent monthly accumulated rainfall and soil moisture. 
Species activity
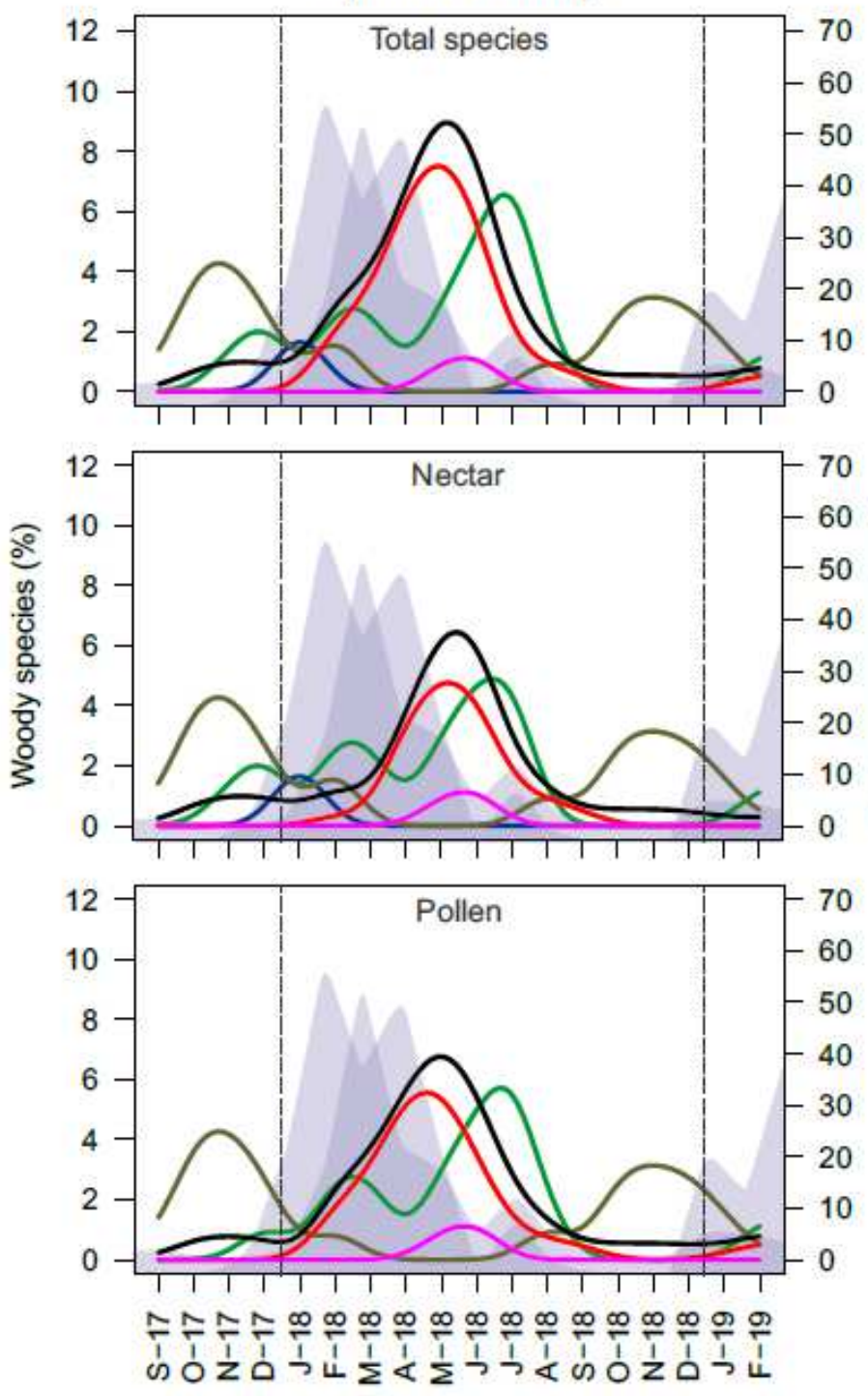

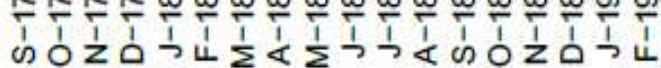

$$
\begin{gathered}
- \text { Community } \\
- \text { Tree }- \text { Shrub }- \text { Liana } \\
- \text { Herb }- \text { Vine }
\end{gathered}
$$

Flowering Intensity
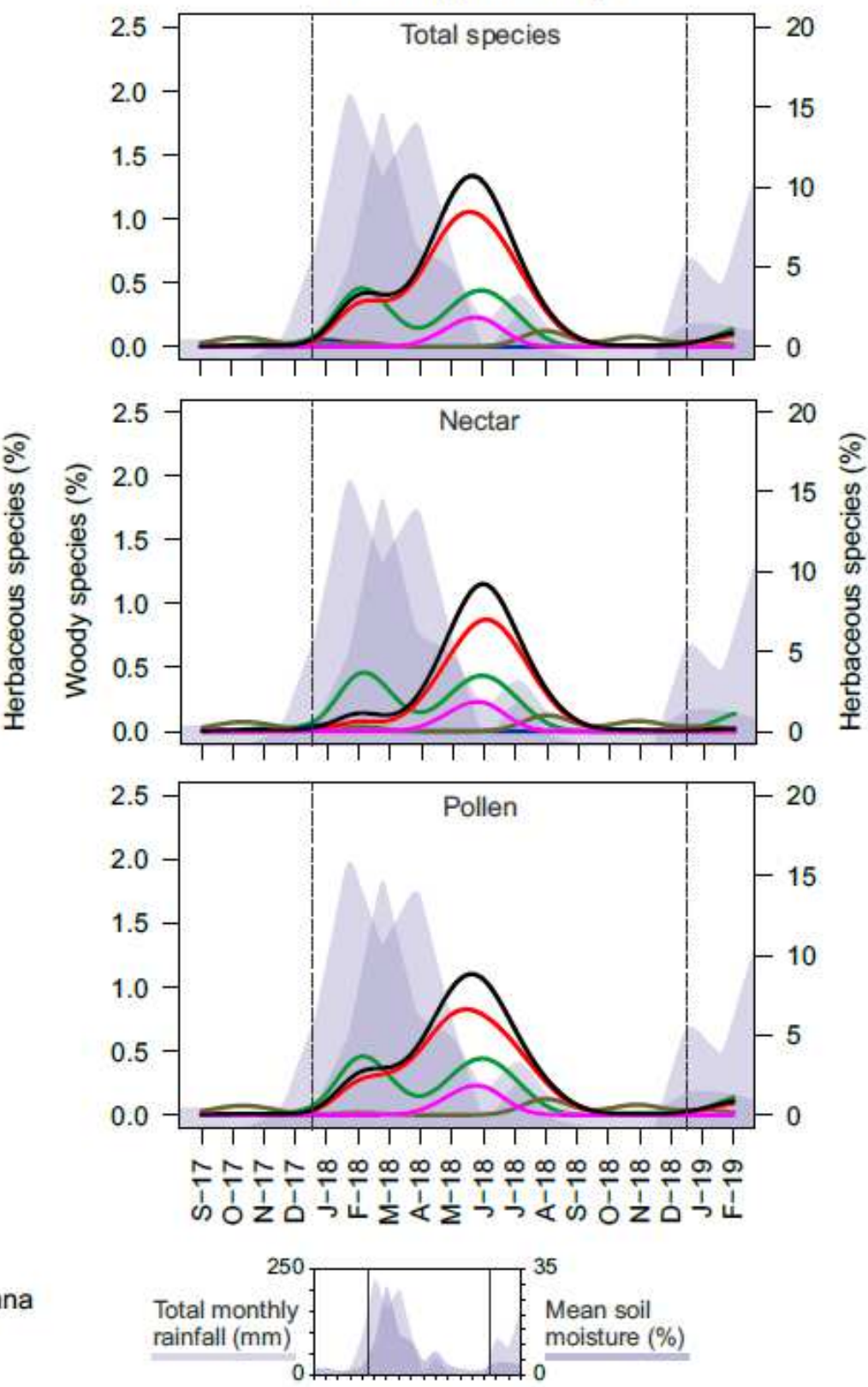

\section{Figure 4}

Phenodynamics of the plant community visited by bees and classified by the type of floral resource (nectar and pollen) according to growth forms in a Tropical Savanna (Caatinga) area in northeastern Brazil. The left side represents species activity (percentage of species bearing flowers), and the right side, flowering intensity (percentage of the canopy with woody individuals bearing flowers of all flowering species and percentage of soil cover with herbaceous plants bearing flowers). The shaded areas in the background represent monthly accumulated rainfall and soil moisture. 

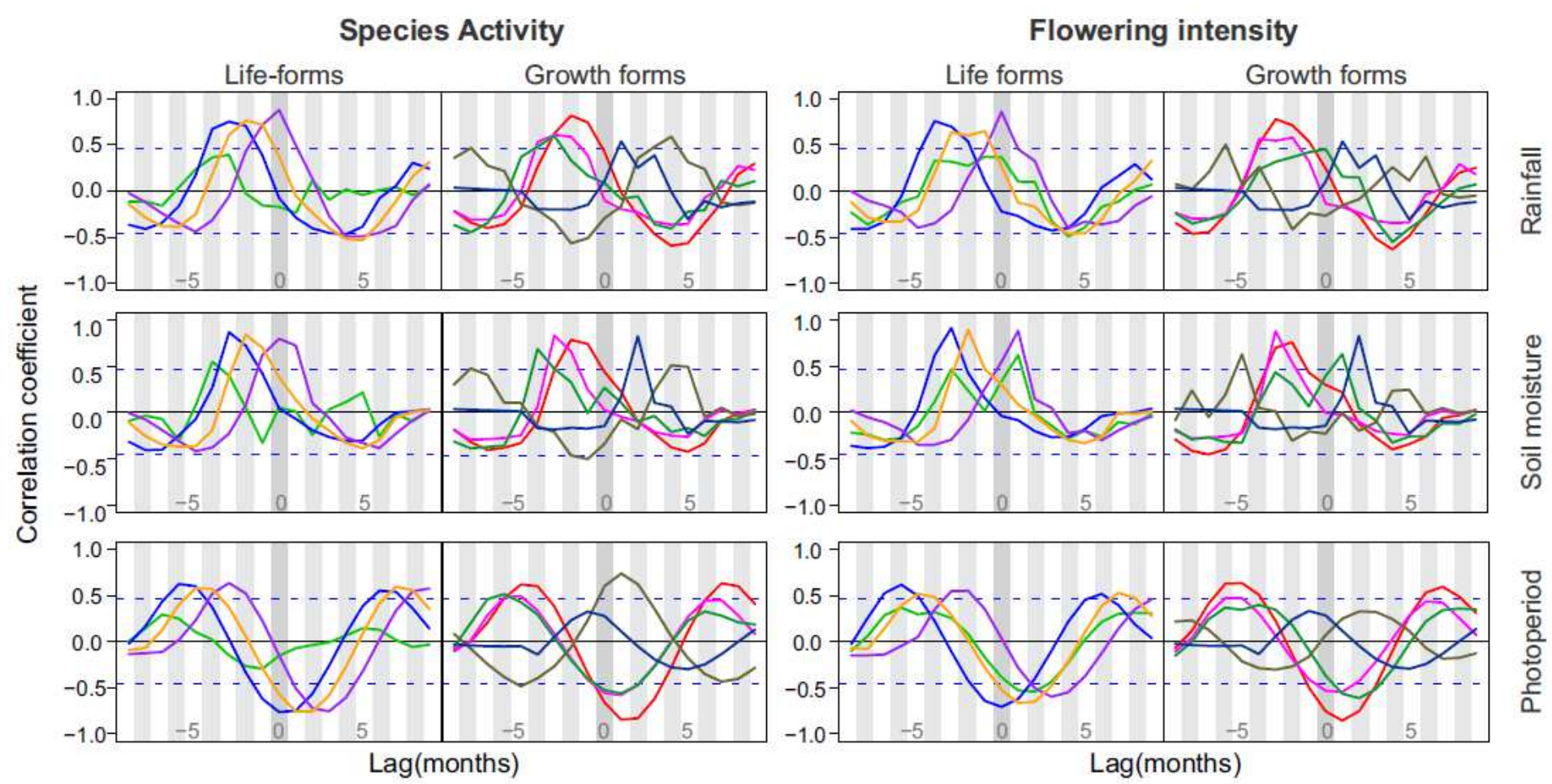

Life-forms: -Phanerophytes_Camephytes - Hemicriptophytes - Terophytes

Growth forms: -Tree - Shrub - Liana - Herb - Vine

\section{Figure 5}

Cross-correlations between phenodynamics (species activity and flowering intensity) of plants visited by bees and abiotic factors (rainfall, soil moisture, and photoperiod) in a Tropical Savanna (Caatinga) area in northeastern Brazil, according to life and growth forms. Significant correlations (bars above the dashed line) on the negative side of the $x$-axis indicate the lag in months in variables' responses to the abiotic factor. Significant correlations on the positive side of the $x$-axis indicate that the phenological event preceded the abiotic factor. Correlation at zero lag indicates a response in the same month of the change in the abiotic factor

\section{Supplementary Files}

This is a list of supplementary files associated with this preprint. Click to download.

- SupplementaryMaterialFigures.pdf

- SupplementaryMaterialTable.pdf 